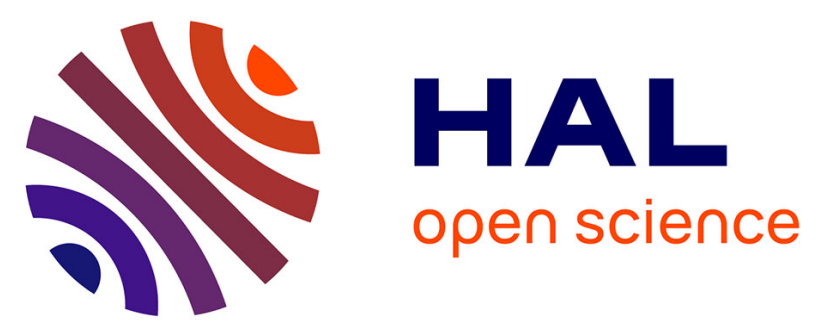

\title{
Role of Homogeneous Catalysis in Oligomerization of Olefins : Focus on Selected Examples Based on Group 4 to Group 10 Transition Metal Complexes
}

Pierre-Alain Breuil, Lionel Magna, Hélène Olivier-Bourbigou

\section{To cite this version:}

Pierre-Alain Breuil, Lionel Magna, Hélène Olivier-Bourbigou. Role of Homogeneous Catalysis in Oligomerization of Olefins: Focus on Selected Examples Based on Group 4 to Group 10 Transition Metal Complexes. Catalysis Letters, 2015, 145, pp.173 - 192. 10.1007/s10562-014-1451-x . hal01119632

\author{
HAL Id: hal-01119632 \\ https://hal.science/hal-01119632
}

Submitted on 27 Feb 2015

HAL is a multi-disciplinary open access archive for the deposit and dissemination of scientific research documents, whether they are published or not. The documents may come from teaching and research institutions in France or abroad, or from public or private research centers.
L'archive ouverte pluridisciplinaire HAL, est destinée au dépôt et à la diffusion de documents scientifiques de niveau recherche, publiés ou non, émanant des établissements d'enseignement et de recherche français ou étrangers, des laboratoires publics ou privés. 


\title{
"Role of Homogeneous Catalysis in Oligomerization of olefins : focus on selected examples based on Group 4 to Group 10 transition metal complexes"
}

\author{
Pierre-Alain R. Breuil, Lionel Magna and Hélène Olivier-Bourbigou* \\ IFP Energies nouvelles, Rond-Point de l'Echangeur de Solaize, BP3, 69360 Solaize, France.
}

\begin{abstract}
Homogeneous olefin oligomerization plays a pivotal role in the field of petrochemistry. Through catalysts, technology and process developments, market requirements in terms of productivity, selectivity and sustainability have been addressed. Over more than 50 years, an intensive research has been devoted to the design of new Group 4 to Group 10 transition metal complexes and to the study of their reactivity towards olefins leading to several breakthroughs of prime importance for academy as for industry. Since the early sixties, IFPEN contributed to bring innovative industrial solutions to different targets from gasoline production to alpha-olefin on purpose processes with over 100 production units built worldwide. Based on nickel, titanium, zirconium or chromium, the catalytic systems for such processes and their next generation are subject to a continuous research where the adaptation of the ligand architecture to the nature of the metal and its mode of activation, play a crucial role to control the reaction selectivity and the catalyst lifetime. Interesting relationships between the complex structure and their reactivity have been drawn and will be discussed on selected examples.
\end{abstract}

\section{I- INTRODUCTION AND SCOPE}

Oligomerization reactions are widely used on an industrial scale to upgrade light olefin streams coming from different hydrocarbon forming processes (steam cracking, FCC, Fischer-Tropsch ...) into heavier olefins that find applications in the field of energy or petrochemistry. This reaction is catalytically achieved by means of different technologies such as heterogeneous acid-catalysis which is essentially applied to the production of fuels or by homogeneous catalytic systems mainly applied to provide high added value chemicals [1].

\section{I.1- Ethylene oligomerization : general market and current commercial technologies}

A few new industrial homogeneous-catalyzed processes have emerged in the past 10 years. An especially growing area of homogeneous catalysis is the oligomerization of short chain alkenes, an important reaction mainly for the synthesis of second generation intermediates (or base materials) for chemical industry. The oligomerization of ethylene to Linear Alpha Olefins (LAOs, even-carbon numbered olefins ranging from $\mathrm{C} 4$ to $\mathrm{C}_{3} \mathrm{O}^{+}$carbon atoms) dominates the market of homogeneouscatalyzed oligomerization. The main applications for the LAOs are as co-monomers for polyethylene production, for oxo-alcohols used in detergent and plasticizers and for the production of poly-alphaolefins for the synthetic lubricant pool. The total world production for LAOs accounted for $3.5 \mathrm{Mt} / \mathrm{V}$ in 2012 for a total capacity of $4.3 \mathrm{Mt} / \mathrm{y}$ (with the exception of 1-butene production from refinery streams). The global annual average growth for LAOs is estimated at 3.3\% (2012-2018) but depends largely on the region with a higher growth in developing countries. Globally, co-monomer grade LAO consumption (C4-C8) is the largest and fastest-growing application, particularly for the production of linear low-density polyethylene resins (LLDPE). Controlling the amount of short-chain branching in the polyethylene polymer through co-monomer addition determines the density of the resin and modifies the processing and mechanical properties of the polymer. As examples, HDPE (High Density PE) uses 2-4 \% of co-monomer (C4-C6), while LLDPE (Linear Low Density PE) uses $8-10 \%$ of comonomer (C4-C8). 1-Butene is still the most used co-monomer, in the commodity end-use applications of LLDPE (more flexible and resilient PE) and to a less extent HDPE. 1-hexene and 1- 
octene are becoming increasingly attractive because of the excellent properties imparted to the copolymer product, including greater stress-crack resistance and tear resistance. For example, LLDPE with 1-hexene leads to tougher film than with 1-butene incorporation and can be produced in a thinner thickness (preferred for packaging application PE). The incorporation of 1-octene gives the highest quality products with good surface finish, good transparency and improved resistance to tearing (produced in solution or slurry-based PE processes).

The global LAO supply is still dominated by the 3 majors, Chevron Phillips Chemical (CPChem), Ineos and Shell, who operate with different catalytic systems, with more or less flexibility (Table 1). These processes are named "full-range processes" because they produce a broad distribution of olefins. The oldest processes use aluminum under harsh reaction conditions of temperature and pressure due to the low activity of aluminum. The first commercial production of LAOs was operated in 1966. The one step process using triethylaluminum catalyst developed by the Gulf Oil Company (now CPChem) produces alpha olefins with a broad Schulz-Flory carbon number distribution. The distribution of olefin chain lengths can be changed (in a certain limit) by altering the reactions conditions. The two-step process (stoichiometric and catalytic steps), known as the Ethyl process (now Ineos) also uses triethylaluminum but leads to a Poisson distribution with a relative narrow distribution of olefins (recycle of butenes to produce higher olefins) and an increased branching olefins in higher fraction (C14-C18). It is the less flexible process in term of product distribution. In these two processes, the olefin streams produced are separated by distillation in quite similar way (in concept). However, an extra demand has appeared for higher quality alpha olefins. This demand is driven by the metallocene polyethylene catalyst and process developments in which the short chain LAOs are used as co-monomers. For this purpose, the alpha-olefin quality upgrade can be achieved by adding a distillation column in the full-range processes. Shell developed the Shell Higher Olefin Process in the 1970s (first commercial use in 1977). In the SHOP process, ethylene is oligomerized to a broad Schulz-Flory distribution of olefins. Compared to the other full-range processes, this process is the most complex but it is quite exceptional because the distribution of oligomers may be adjusted through isomerization and metathesis consecutive steps to meet the required linear internal olefins chain length (applications for detergents and plasticizers). The processes catalyzed with zirconium based complexes have emerged later. Idemitsu Kosan Co. Ltd. developed an oligomerization process catalyzed by a system based on a zirconium(IV) complex associated with an chloroalkylaluminum derivative and a Lewis base. This process was commercialized in 1989. IFP Energies nouvelles (IFPEN) and SABIC-Linde both separately developed processes based on a Ziegler-Natta catalytic system composed of a zirconium precursor, a proprietary ligand and an aluminum co-catalyst. The SABICLinde technology was operated at SABIC in 2009.

Table 1: LAOs by ethylene oligomerization processes - technology and market survey [2]

\begin{tabular}{|c|c|c|c|c|}
\hline $\begin{array}{l}\text { Company } \\
\text { (industrial) }\end{array}$ & Type of catalyst & $\begin{array}{c}\text { Typical LAO } \\
\text { distribution (wt. \%) }\end{array}$ & $\begin{array}{l}\text { World capacity } \\
(2012, \mathrm{kt} / \mathrm{y})\end{array}$ & $\begin{array}{l}\text { Announced new capacities } \\
(>2012, \mathrm{kt} / \mathrm{y})\end{array}$ \\
\hline CPChem & $\begin{array}{c}\mathrm{AlEt}_{3} \\
\text { (1 step) }\end{array}$ & $\begin{array}{l}C_{4}-C_{10}=54(49)^{(\text {a) }} \\
C_{12}-C_{14}=18(18) \\
C_{16}-C_{20+}=28(33)\end{array}$ & 1053 & 140 \\
\hline Ineos & $\begin{array}{c}\mathrm{AlEt}_{3} \\
\text { (2 steps) }\end{array}$ & $\begin{array}{c}\mathrm{C}_{4}-\mathrm{C}_{10}=70-77 \\
\mathrm{C}_{12}-\mathrm{C}_{14}=21-28 \\
\mathrm{C}_{16}-\mathrm{C}_{20+}=2\end{array}$ & 565 & 375 \\
\hline Shell & $\begin{array}{c}\mathrm{Ni} / \mathrm{P}-\mathrm{O} \\
\text { (biphasic) }\end{array}$ & $\begin{array}{c}C_{4}-C_{10}=54(32)^{(a),(b)} \\
C_{12}-C_{14}=18(16) \\
C_{16}-C_{20+}=28(52)\end{array}$ & 1251 & 650 \\
\hline Idemitsu & $\begin{array}{c}\mathrm{Zr} / \mathrm{L} / \mathrm{AlR}_{3-\mathrm{x}} \mathrm{Cl}_{\mathrm{x}} \\
\text { (solvent) }\end{array}$ & Non disclosed & 60 & 330 \\
\hline SABIC/Linde & $\begin{array}{l}\mathrm{Zr} / \mathrm{L} / \mathrm{AlR}_{3-\mathrm{x}} \mathrm{Cl}_{\mathrm{x}} \\
\text { (solvent) }\end{array}$ & $\begin{array}{l}C_{4}-C_{10}=82(26)^{(\text {a) }} \\
C_{12}-C_{20+}=18(74)\end{array}$ & 250 & 37 \\
\hline
\end{tabular}

(a) Typical distribution, in brackets possible flexibility (b) possible distribution of LAOs after oligomerization and before isomerization and metathesis processing 
In Table 1, the additional estimated new capacities for LAOs using these existing technologies are also mentioned. The applications of the additional capacities are mainly for the polyethylene market but other applications, such as poly-alpha-olefins, oil drilling fluids and surfactants can also contribute to the growth.

\section{I.2- Main recent industrial developments in the field}

Today, the oligomerization of ethylene ("full-range" processes) is the predominant route to produce LAOs. However, as the demand for short-chain C4 to C10 linear alpha olefins is growing faster than that for the $\mathrm{C}_{10} 0^{+}$range, significant recent progresses have been made to control the product distribution to shorter alpha olefin distributions (flexibility of the most recent Zr-based processes) or even to produce selectively one main alpha-olefin such as 1-butene, 1-hexene or 1-octene. Transition metal homogeneous catalysis again opens the door to the development of new selective oligomerization processes. These selective processes are called "on purpose" technologies. Some of these technologies have recently been commercialized or industrialized (Table 2).

Table 2: "On purpose" processes ${ }^{(a)}$ for the selective production of 1-butene, 1-hexene and 1-octene

\begin{tabular}{|c|c|c|c|}
\hline LAO produced & Process/company & Catalyst type & Capacity (kt/y) $^{(\mathbf{b})}$ \\
\hline 1-Butene & AlphaButol/Axens & Ti/AlR & 708 \\
\hline 1-Hexene & CPChem & Cr proprietary/AIR & 397 \\
\hline 1-Hexene & AlphaHexol/Axens & Cr proprietary/AlR & $50^{(\mathrm{c})}$ \\
\hline 1-Hexene & Mitsui & Ti proprietary /"MAO" & 30 \\
\hline 1-Octene/1-Hexene & Sasol & Cr proprietary/ "MAO" & 100 \\
\hline
\end{tabular}

(a) only commercialized processes are cited here (b) include planned capacities (c) total capacity for 2 units AlphaButol et AlphaHexol

It is now generally accepted that the mechanism for the selective ethylene transformation into 1hexene and 1-octene goes through a metallacycle formation as illustrated in Scheme 1 (route A). On the other hand, the generalized mechanism for the "full-range process" occurs via a degenerated polymerization route as shown in Scheme 1 (route B). Discussion is still open for 1-butene production.

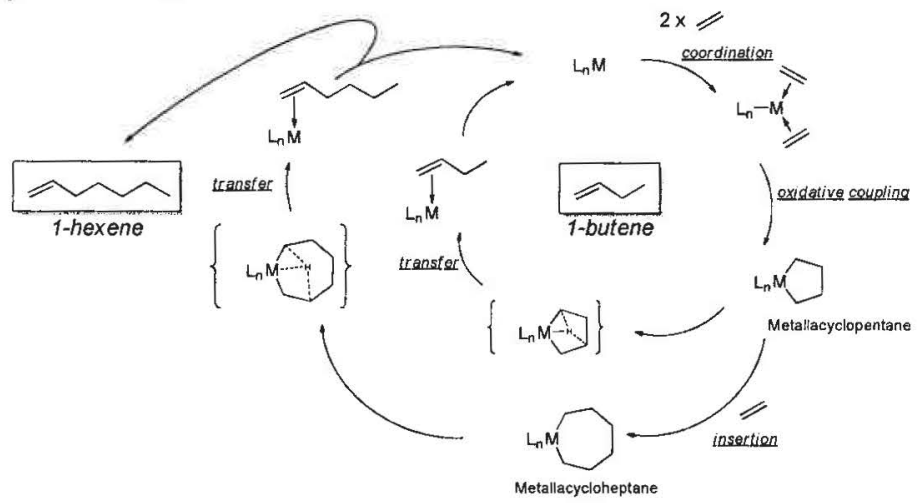

Route A

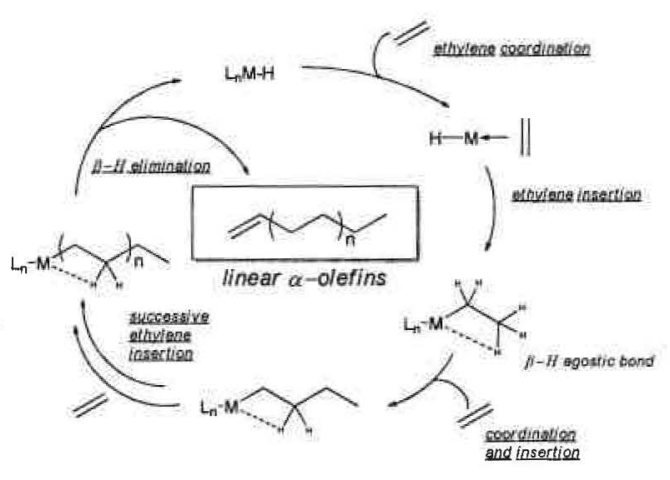

Route B

Scheme 1 : Ethylene oligomerization mechanisms - metallacycle pathway (route A), degenerative polymerization (route B)

Today, there is an increased availability of natural gas [3], especially in North America with the shale gas exploration. The large production of shale gas in the US had the effect of reducing the US natural gas prices, making ethane supply abundant, increasing the use of lighter feed in the crackers and contributing to the construction of new ethane crackers. Globally, this has contributed to a growing 
price gap between crude oil and natural gas. This dynamic makes lighter feedstock derived from natural gas (like ethane) more attractive input for cracking operations, compared to heavier feedstock derived from crude oil (like naphtha). The shift toward greater use of these lighter feedstock has resulted in the production of significantly less C3 and C4 fractions which could generate a shortfall for certain major intermediates. If most 1-butene is today still supplied from refinery sources (extraction from C4 fraction), one can expect that in the future, the "on purpose" production via selective dimerization processes will become predominant.

\section{I.3- IFPEN achievements in olefin oligomerization}

Since the early sixties [4], IFPEN has been deeply involved in the search of innovative homogeneous transition metal based catalytic systems. In 1977, the first Dimersol industrial plant was put onstream in the United States producing gasoline by oligomerization of propylene coming from a Fluid Catalytic Cracking C3 fraction. This reaction was catalyzed by a homogeneous Ziegler-Natta nickelbased catalyst. In the 1980 s, a new challenging activity was to selectively dimerize ethylene into 1butene, the most popular key ethylene co-monomer for manufacturing LLDPE and HDPE to a less extend. An efficient soluble titanium-based complex was designed. The first AlphaButol industrial unit was started up in 1986 in Thailand. The demand and annual growing rates for LAOs, motivated the development of a "full-range" ethylene oligomerization process. Ziegler-Natta type systems based on zirconium complexes were chosen for this purpose leading to the AlphaSelect process. In the mid-1990s, a research was initiated at IFPEN in one of the most promising recent area in liquid phase homogeneous catalysis: the use of non-conventional, non-aqueous ionic liquids for biphasic catalysis. This new technology, trade-named Difasol, was successfully applied to the nickel-catalyzed butene or propylene selective oligomerization/dimerization making possible a better use of the catalyst associated with a more efficient process scheme. The market demand for 1-hexene drove our research, in the 1990s, to the design of a selective trimerization catalyst. An efficient catalytic system based on chromium associated with a low investment cost process were developed and optimized to produce high purity 1-hexene. The first AlphaHexol unit was commercialized in 2012 [5]. Ethylene is mainly originating from steam cracking. Fluctuating steam cracking traditional ethylene prices as well as consumer orientation toward renewable materials initiated our search for new resources able to bridge the gap between bio-based and traditional petrochemicals. One of these resources is bio-ethanol. Using bio-ethanol feed based on non-food biomass (also called $2^{\text {nd }}$ generation resource), enables to produce ethically acceptable and renewable plastics with the same properties and recyclability as existing polyethylene grades. A process chain encompassing ethanol to ethylene technology and "on purpose" alpha-olefin processes (e.g. AlphaButol or AlphaHexol) was fitted in to develop a complete process portfolio to turn bio-ethanol in $100 \%$ bio-polyethylene containing $100 \%$ bio co-monomers.

\section{I.4- Scope of the review}

Since the early days, important work has been devoted to the design of new transition metal complexes and to the study of their reactivity towards olefins, mainly ethylene. However, during these last years, interest grew in developing new generation of catalysts with the aim of a greater control of the selectivity towards the desired linear alpha olefins. The architecture of the ligands, which have to be adapted to the nature of the metal, plays a crucial role. The recent past years have seen a growth in the design of versatile multidentate ligands. Several studies have clearly demonstrated that even minor variations on the steric and electronic properties of these ligands and the geometrical constraints they impose on the metal can lead to great changes in catalytic reactivity such as oligomerization vs polymerization, initial activity (TOF), productivity (TON) as well as catalyst stability and lifetime. Interesting relationships between molecular structures of the complex precursor and their reactivity have in some cases been drawn. However, it should be noted that most of the catalysts used in oligomerization are based on Ziegler-Natta type systems, a multi-component 
combination of a metal precursor and a suitable activator such as an alkylaluminum derivative. In the open literature, the molecular structures generally depict the catalyst precursor, which has to be activated to form the catalytically active species. This pre-catalyst activation is determining and directs the following catalytic steps. There is generally only limited direct information on the nature and the structure of the active species. The introduction of MAO as a suitable activator for transition metals ( $\mathrm{Gr} 4$ to $\mathrm{Gr} 10$ ) oligomerization was a major breakthrough but it also introduced an important issue with regards to the elucidation of the nature of the active species involved.

Few reviews dealing specifically with olefin oligomerization were published $[6,7,8,9]$. The aim of this present review is not to give an exhaustive overview of the recent developments in the field of oligomerization. This review highlights some selected examples based on our own achievements in the light of the major industrial developments. The catalytic systems are classified according to their industrial importance, across different families of ligands. In the group 10, nickel is the most described and used oligomerization catalyst with a considerable number of publications. It is applied in three different industrial processes currently in operation for different purposes. In the review, we choose to take the nature of the nickel active species as the main theme to exemplify its reactivity and use. Group 6, particularly chromium, has seen a particular growth in research activity this last years. The chromium chapter focuses on the industrial developments and the key ligand design developed. Metals from group 4, particularly titanium, are illustrated with a "cyclopentadienyl/phenoxy" ligand oriented research. The new developments regarding iron are then presented. Finally, tungsten even if it was not applied in industry in the oligomerization field up to now is discussed. Despite some very recent examples tantalum [10] as well as vanadium [11] catalysts are not treated here. It is worth underlining that no heterogeneous or supported catalyzed processes emerged for ethylene oligomerization despite the numerous studies published in this field from both academia and industry.

\section{II- NICKEL INDUSTRIAL DEVELOPMENTS AND FUTURE CHALLENGES}

The nickel catalyzed olefin oligomerization has a long history [12]. The discovery of the "nickel effect" by Wilke [13] was the beginning of the major Ziegler's breakthrough who observed that nickel salts

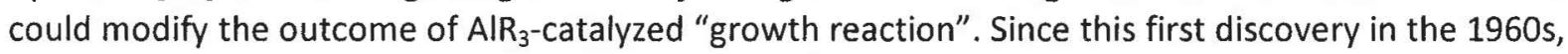
nickel is still playing a central role in the late-transition metal catalysts for olefin oligomerization and polymerization and continues to be one of the most studied metal in this field both by academic and industrial laboratories [14]. The interest has mainly been focused on the ligand design. A myriad of multifunctional ligand backbones has been reported including phosphorous, nitrogen and/or oxygen heteroelements. A large number of nickel(II) pre-catalysts were described opening to a very rich coordination chemistry. This chapter does not cover these developments which have already been reviewed $[9,14]$.

With regards to the nature of the active nickel species, two main families have so far been recognized, according to the nature of the ligand bonding around the nickel metal: neutral and cationic nickel catalysts (Figure 1). Cationic nickel active species (type A) are electronically unsaturated and highly electrophilic. They involve nickel (II), incorporate a donor ligand and are generally four coordinated with a square planar geometry. They are difficult to isolate because of their high reactivity. Cationic $\pi$-allyl nickel complexes have nevertheless been isolated by Wilke [15] and can be considered as a model of this kind of active species. It is worth noting that the neutral $\pi$ allyl nickel halide complexes are not active towards olefin. However, combined with Lewis acids such as aluminum halides, they are active homogenous catalysts for the dimerization of ethylene and propylene and the polymerization of butadiene. The transfer of the halide from the nickel to the aluminum results in the formation of an electrophilic cationic metal center and formation of a free coordination position on the nickel on which the olefin can coordinate. Neutral nickel catalysts (type B) are less electrophilic than those of the cationic family. They commonly contain anionic type ligands 
(oxygen or nitrogen based) and a $\mathrm{Ni}-\mathrm{C}$ or $\mathrm{Ni}-\mathrm{H}$ active bond in which the olefin will insert to begin the catalytic cycle.

These two kinds of nickel catalysts independently led to the main still currently performed industrial nickel-catalyzed oligomerization processes: Dimersol/Difasol and Phillips processes (Figure 1, type A) and SHOP process (Figure 1, type B). These industrial processes are first briefly described. Then, further developments on the design of ligands will be discussed.

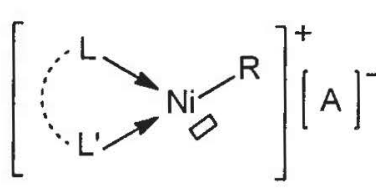

Type A

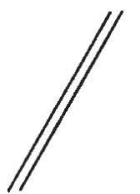

(1)<smiles>[X][N+]1([R])[AlH]CCC[V]1[3H]</smiles>

Type B

$$
\text { with }\left\{\begin{array}{l}
R=\text { hydrocarbyl group or } H \\
X=\text { anionic ligand } \\
L, L^{\prime}=\text { electron donor ligands }
\end{array}\right.
$$

Figure 1 : The two main families of Ni active catalysts

\section{II.1- The Dimersol/Difasol and Phillips processes : Ni catalysts of type A}

The Dimersol process: Ni(II)/EtAlCl

The industrial Dimersol process [16] was developed by IFPEN to convert light olefins (ethylene, propylene and/or butenes) into liquid olefin oligomers for the production of high octane sulfur free gasoline ( $\mathrm{C} 6$ olefins predominate) and for the production of $\mathrm{C} 8$ olefins used for isononylalcohols (INA) manufacture dedicated to the plasticizer market. Some gasoline Dimersol units are still in operation despite the planned restriction of olefin level in gasoline and the increasing demand of propylene for petrochemistry. The $\mathrm{C} 8$ olefins produced from butenes in Dimersol units constitute good quality feeds for oxonation reaction because of their low branching index (production of INA). The INAs produced by this route are of special interest and competitive alternatives to the 2-ethylhexanol (propylene oxonation) the demand of which is decreasing in some regions because of the health issue of the DEHP (DiEthylHexylPhthalate) phthalate plasticizers.

The Dimersol reaction is catalyzed, in the liquid phase, by a homogeneous nickel complex which results from the interaction of a $\mathrm{Ni}(I I)$ precursor with a chloroethylaluminum compound. The nickel active species is of type $\mathrm{A}$ (Figure 1). The alkylaluminum co-catalyst has a dual role: to alkylate the $\mathrm{Ni}$ complex to form the $\mathrm{Ni}-\mathrm{H}$ bond after $\beta-\mathrm{H}$ elimination and to capture the anionic ligand from the $\mathrm{Ni}$ to generate the counter-anion of the cationic $\mathrm{Ni}$ complex. The active species is formed inside the oligomerization reactor under olefin atmosphere. The most frequently encountered mechanism for nickel catalyzed oligomerization is the degenerated polymerization mechanism well described by Cossee and Arlman (Scheme 1). The reaction products are mainly composed of dimers due to the high rate of termination step. The reaction is non-(regio)selective and leads to a mixture of the different dimeric isomers. In the case of propylene or butenes conversion, the formed dimers are mainly mono methyl branched internal olefins (methylpentenes and methylheptenes, respectively). Isomerization of the double bond occurs as a side reaction catalyzed by the active $\mathrm{Ni}-\mathrm{H}$ (insertion of the dimer in $\mathrm{Ni}-\mathrm{H}$, followed by $\mathrm{\beta}-\mathrm{H}$ elimination). The heavier product formation mainly originates from consecutive co-dimerization of the monomer with the formed dimers. These consecutive reactions are favored at high monomer conversion.

In this type of nickel catalysis, the main challenges are focused to reach high conversion and high selectivity for the dimers. The type of reactor technology (CSTR vs plug flow) has a significant impact on the oligomer by-product formation which results from consecutive reactions [12]. 
It has to be borne in mind that beside the addition of ligands, the process design can impact the formation of these by-products and that some advances can also be proposed to optimize the dimer yield by that way. This has been one of the drivers of the development of biphasic catalysis.

\section{The biphasic Difasol process: Ni(II)/Chloroaluminate ionic liquids}

In the early 1990s, biphasic liquid catalysis appeared as a highly attractive approach to solve some of the main issues of homogeneous catalysis such as the catalyst recovery and recycle. The cationic nature of the active nickel species and the use of chloroalkylaluminum compounds as activators prompted us to investigate acidic chloroaluminate ionic liquids as possible medium to perform the reaction. At that time, chloroaluminates were mainly applied as electrolytes [17]. It was the first time that these ionic liquids were used as a combination of solvent and co-catalyst for a chemical reaction [18]. The addition of ethyl aluminum dichloride $\left(\mathrm{EtAlCl}_{2}\right)$ to the acidic chloroaluminate was found to form anionic mixed alkylchloroaluminate anions that inhibit the formation of higher oligomers due to a cationic side reactions [19]. Compared to the homogeneous single-phase reaction, the biphasic process in chloroaluminates, named Difasol, led to a higher selectivity into octenes (> $90 \mathrm{wt}$. \% of octenes relative to the total products even at $80 \%$ butene conversion). In such system, consecutive side reactions (octenes + butenes) are minimized as a consequence of the lower solubility of octenes compared to butenes in the ionic liquid. Moreover, the reaction could be performed with diluted feeds (butenes + isobutene or butane) with the same performances in terms of productivity. The demonstration of the stability of chloroaluminates and nickel under catalytic conditions was achieved via a continuous long term pilot run. The product separation operated by setting was efficient and no significant loss of ionic liquid in the product phase could be detected [20]. The Difasol technology [21] can extend the field of applications of the Dimersol to the less reactive longer chain olefins such as $\mathrm{C} 5$ fractions allowing the production of decenes or nonenes through co-dimerization of $\mathrm{C} 4$ and $\mathrm{C5}$ olefins.

The advantages brought by the biphasic approach can be all the more important since costly phosphine ligands are used in excess without recycling. This is the case of the sterically demanding basic tricyclohexyl phosphine involved in the homogeneous Ni-catalyzed propylene dimerization to favor the formation of 2,3-dimethylbutenes (2,3-DMBs, tail-to-tail dimers). 2,3-DMB-1 and 2,3-DMB2 are key industrial intermediates for fine chemical synthesis (musk fragrance or insecticide) [22,23]. We switched this reaction into chloroaluminates and operated successfully the catalysis in a continuous biphasic way [24]. The main issue was to maintain the phosphine effect with time while optimizing the phosphine consumption. This was achieved by the addition of small amount of a weak organic base which acts as a buffer of chloroaluminate acidity. A new biphasic continuous flow process for the regio-selective dimerization of propylene into 2,3-DMB-1 was developed by IFPEN. Total hexene selectivity was hold steady at 75-80 wt. \% hexenes/total products and 2,3-DMB-1 was hold steady at $70-75$ wt. \% relative to the total hexene content [19].

\section{The Phillips process : Ni(II)/P(n-Bu $)_{3} / \mathrm{EtAlCl}_{2}$}

$\mathrm{Ni}$ homogeneous Ziegler-Natta systems based on $\mathrm{Ni}(\mathrm{II})$ and a chloroalkylaluminum were very early disclosed to catalyze the oligomerization of olefins, such as ethylene. In these early days, there was a lot of patents in this field assigned to different companies [8]. However, nickel catalysts were not highly selective for the formation of dimers (e.g. butenes from ethylene) affording too important undesirable and wasteful quantities of side products such as higher oligomers. In the late 1960s, Phillips Petroleum company [25] disclosed a process which converts ethylene selectively into 2butene. A typical catalyst composition consists of bis(tri- $n$-butylphosphine)nickel dichloride and ethylaluminum dichloride. The Al to $\mathrm{Ni}$ molar ratio has an important impact on the reaction selectivity. It is described that ethylene dimerization takes place in a circulating loop reactor under mild reaction conditions $\left(P=10-15\right.$ bars and $\left.T=35-45^{\circ} \mathrm{C}\right)$. High velocities are maintained in the reactor to minimize fouling and temperature rise across the reactor. 
Monophosphines have been largely studied in nickel-catalyzed oligomerization field and the well described phosphine effect has been applied in two main industrial processes for the production of 2,3-DMB and 2-butene. However, one main issue of these systems is the loss of the phosphine effect with time which results from the de-coordination of the ligand from the nickel metal center, particularly when excess of Lewis acid aluminum compounds are used as co-catalyst.

To circumvent this issue, different strategies have been developed. One of them consists in using bidentate neutral ligands ( $L-L$ or $L-L^{\prime}$ ) which combine interesting properties in catalysis and stabilization of the metal. A large number of ligands such as P-P, P-O, P-N,... have been reported [9]. Nickel usually forms four-coordinated complexes with these ligand systems while a few five coordinated complexes have been reported. If we make a focus on diphosphines, we can see that they have largely been evaluated in nickel catalyzed oligomerization. However, examples of dissymmetrical diphosphines and their corresponding nickel complexes are scarce maybe due to their tedious synthesis. We recently described a metal-induced rearrangement strategy from iminobisphosphine ligands to symmetrical and non-symmetrical diphosphinoamine nickel complexes (Scheme 2) [26]. Upon activation with MAO, these unprecedented complexes oligomerize ethylene to small chain oligomers (mainly $\mathrm{C} 4-\mathrm{C} 8$ ) with high productivity, highlighting the prime importance of introducing alkylphosphine moieties in such pre-catalysts.

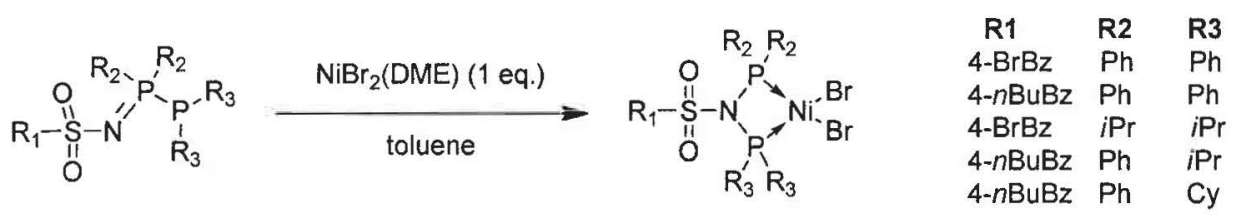

Scheme 2 : Symmetrical and non-symmetrical diphosphinoamine nickel complexes

An interesting approach to generate the active $\mathrm{Ni}-\mathrm{H}$ cationic species is via oxidative addition of a Brönsted acid to a $\mathrm{Ni}(0)$ precursor [27]. This combination promotes ethylene oligomerization in organic solvent but with very low activity. However, the reaction activity can be enhanced by using ionic liquids as solvents. We were nevertheless surprised to observe that in [1-butyl-3methylimidazolium] $\left[\mathrm{NTf}_{2}\right]$ ionic liquid $\left(\mathrm{NTf}_{2}=\right.$ bis[(trifluoromethane)sulfonyl]amidure), ethylene was transformed into butenes without any addition of acid. The formation of active nickel complex was explained by an oxidative addition of the imidazolium cation to the $\mathrm{Ni}(0)$ to form in situ a [(NHC)Ni$\mathrm{H}^{+}\left[\mathrm{NTf}_{2}\right]^{-}$species ( $\mathrm{NHC}=\mathrm{N}$-heterocyclic carbene) [28]. NHC carbene are versatile ligands that share many of the coordination properties with the phosphines with which they are frequently compared. They present stronger sigma-donating properties that can stabilize late transition metal complex. Nickel complexes bearing 1,3-dialkylimidazolin-2-ylidene carbene have been reported for the olefin oligomerization $[29,30]$ (Figure 2). Upon activation with chloroalkylaluminum derivatives in toluene, these complexes are inactive to sparingly active. On the other hand, they are highly active in acidic chloroaluminate ionic liquids. However, disappointingly, they do not present any regio-selectivity with propylene unlike the $\left[\mathrm{NiCl}_{2}\left(\mathrm{PC}_{3}\right)_{2}\right]$ complex in the same conditions.

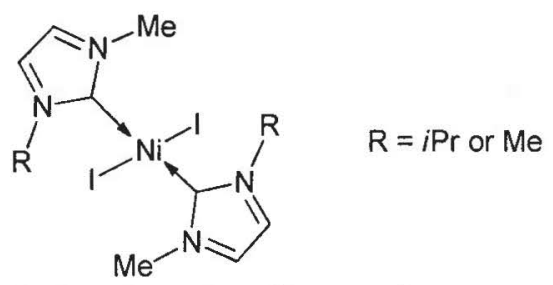

Figure 2: Examples of non-functionalized "Ni-NHC" complexes evaluated in catalysis 
Moreover, catalyst deactivation occurs rapidly because of the facile reductive elimination of the NHC ligand via the formation of a 1,3-dialkylimidazolium cation bearing an ethyl substituent on the $C(2)$ carbon [31].

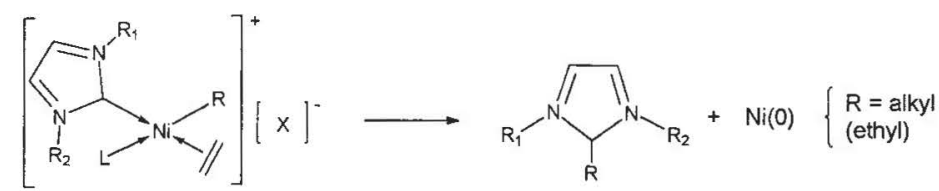

Scheme 3: Deactivation of "Ni-NHC" complexes by reductive elimination

Guy Bertrand and co-workers have developed a new type of versatile carbenes: the cyclic alkyl amino carbenes (CAAC) [32]. These ligands are more electron donating and bulkier than classical NHC and phosphines. The synthesis of the corresponding iminium salts is quite simple $[33,34]$ so that we anticipated that CAAC could be perfect candidates for their use as ligands on nickel complexes to form new efficient catalysts in propylene dimerization. The $\left[\mathrm{NiCl}_{2}\left(\mathrm{PCY}_{3}\right)_{2}\right]$ complex, partially soluble in toluene, can be used as starting material for "Ni-CAAC" synthesis. For example, the addition of 2 equivalents of CAAC to $\left[\mathrm{NiCl}_{2}\left(\mathrm{PCY}_{3}\right)_{2}\right]$ complex allowed to isolate a new bis(CAAC)nickel(II) complex, soluble in heptane (Scheme 4), the molecular structure of which was determined by single-crystal Xray analysis (Figure 3). The carbene ligands are situated trans to each other and the geometry is slightly distorted square planar [35].

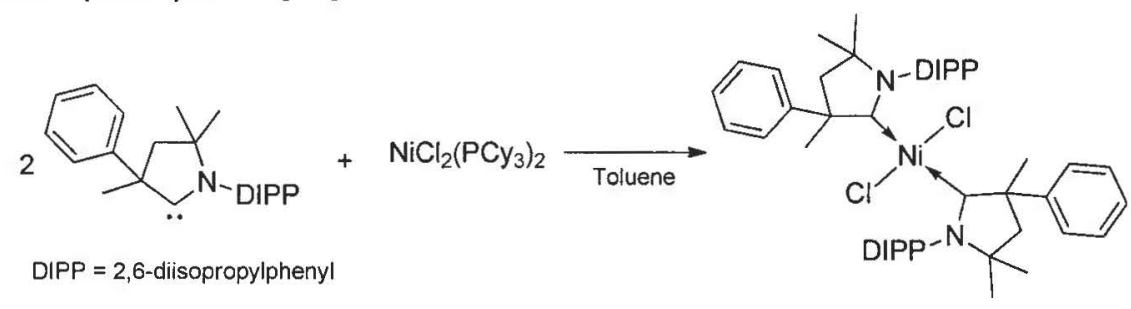

Scheme 4: Synthesis of $\left[(C A A C)_{2} \mathrm{NiCl}_{2}\right]$

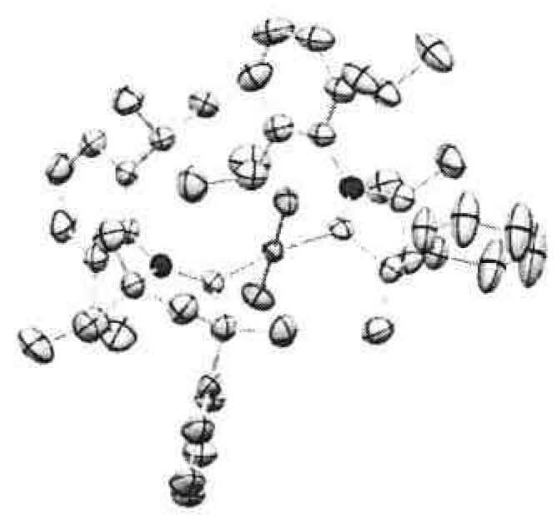

Figure 3: ORTEP view of [(CAAC) $\left.{ }_{2} \mathrm{NiCl}_{2}\right](C \mathrm{CDC} 1030813) . \mathrm{H}$ atoms omitted for clarity. Thermal ellipsoids include $50 \%$ of the electron density.

Starting from the pale green insoluble $\left[\mathrm{NiCl}_{2}, 2 \mathrm{Pyridine}\right]$ complex, a new mixed complex $\left[\mathrm{NiCl}_{2}(\mathrm{CAAC})(\mathrm{Pyr})\right]$ could be isolated in low yield despite many attempts of synthesis optimization (Scheme 5). The X-ray structure of this violet complex shows a distorted tetrahedral geometry [36] (Figure 4). 


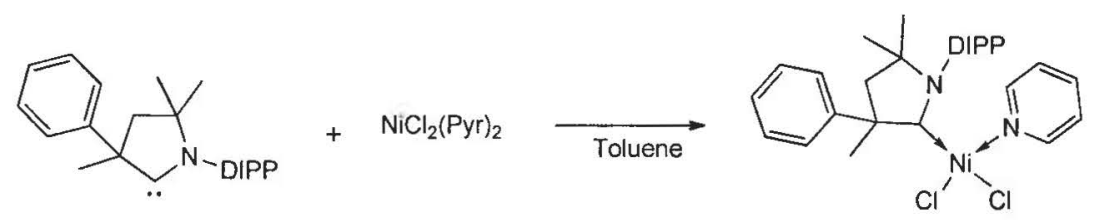

DIPP = 2,6-diisopropy|pheny

Scheme 5 : Synthesis of $\left[(\mathrm{CAAC})(\mathrm{Pyr}) \mathrm{NiCl}_{2}\right]$
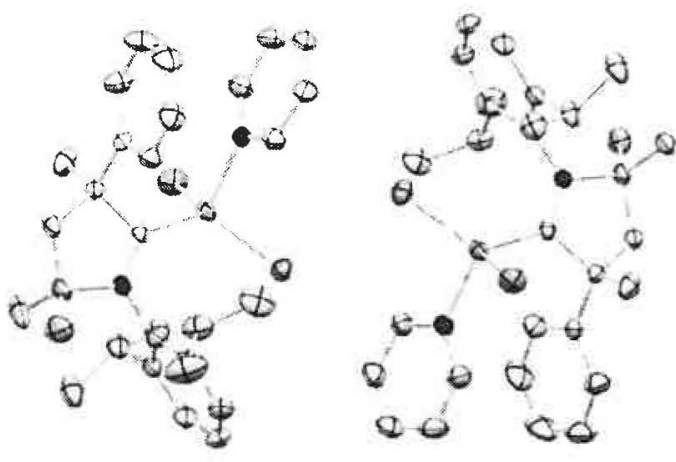

Figure 4 : ORTEP view of $\left[(\mathrm{CAAC})(\mathrm{Pyr}) \mathrm{NiCl}_{2}\right](\mathrm{CCDC} 1030814) . \mathrm{H}$ atoms omitted for clarity. Thermal ellipsoids include $50 \%$ of the electron density

The two "Ni-CAAC" complexes were evaluated in propylene dimerization in homogeneous or biphasic system using acidic chloroaluminate ionic liquids. Upon activation with $\mathrm{EtAlCl}_{2}$, both complexes present an activity but are less active than $\left[\mathrm{NiCl}_{2}\left(\mathrm{PC}_{3}\right)_{2}\right]$ used in similar operating conditions. Moreover, the "Ni-CAAC" complexes do not display any regio-selectivity and form methylpentenes as the major isomers.

To reduce deactivation pathway with monodentate carbene, one strategy consists in attaching a donor function to the NHC to form a heterobidentate (L-L') ligand which could undergo hemilabile behavior. Ether-functionalized NHC ligands have recently been studied [37]. The corresponding biscarbene nickel(II) complexes have been isolated and characterized by X-ray analysis. No inter- or intra-interaction between the ether function and the metal was observed. These complexes promote ethylene oligomerization upon activation with $\mathrm{EtAlCl}_{2}$ but they did not lead to remarkable activity.

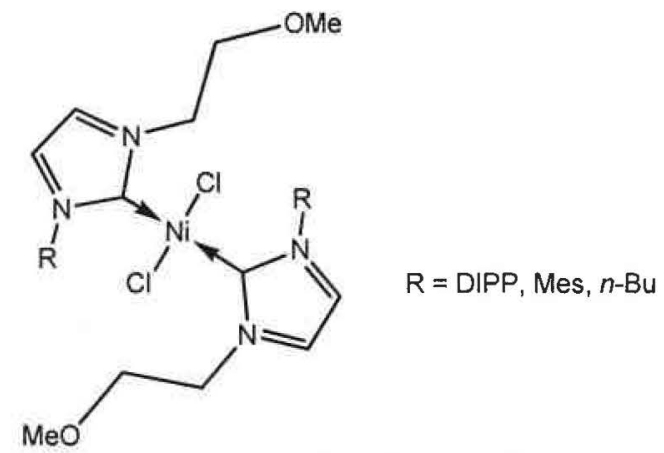

Figure 5 : Examples of functionalized "Ni-NHC" complexes

Toward nitrogen ligands : Versipol complexes and analogues 
For a long time, nickel complexes, as other late transition metal complexes, have been considered to be less prone to polymerization and to preferentially lead to olefin oligomerization because of their propensity to generate $\beta$-elimination, in contrast to $\mathrm{Ti}$ and $\mathrm{Cr}$ which were good polymerization catalysts. However, the discovery in the late 1990 s that, upon activation with MAO, $\alpha$-diimine nickel(II) complexes were highly active catalysts for ethylene oligomerization as well as for polymerization [38], changes the simple picture of the nickel and triggered a true exploration of the late-transition metal catalysts for olefin polymerization. In oligomerization, the activity of these systems is very high (activity up to $1370000 \mathrm{~g}_{\mathrm{C} 2 \mathrm{H}} /\left(\mathrm{mol}_{\mathrm{Ni}} \cdot \mathrm{h}\right.$ ) upon activation by MMAO, Schulz-Flory distribution of olefins with $\alpha$-selectivity up to $94 \%)$. Moreover, $\alpha$-dimine ligands are versatile and easy to synthesize which made these systems very popular. The Schulz-Flory distribution of the olefins can be modulated in a certain limit ( $K$ values range from 0.59 to 0.81 ). The alpha selectivity of the olefins depend on the operating conditions but are generally lower ( $96 \%$ for the highest) than the quality required for the LAO. The isomerization ability of cationic Ni hydride cannot be completely avoided.<smiles></smiles>

Figure 6: Example of "Ni-diimine" complexes evaluated in ethylene oligomerization

Other functionalized nitrogen-based ligands (pyrazole, imidazole, oxazole, ...) with interesting coordination chemistry have also attracted attention for Ni-catalyzed oligomerization but none of them really differentiate in term of terminal olefin selectivity (> $95 \%$ alpha olefin) $[14,39]$. Nevertheless, pyridine functionalized ligands remains quite interesting. Reliance reported few years ago the use of pyridine-oxime derivatives (Figure 7). Associated to nickel and activated by MAO or $\mathrm{Et}_{2} \mathrm{AICl}$, these ligands were surprisingly found to be particularly active and highly selective for the production of 1-butene (up to $92 \%$ of $\mathrm{C} 4$ and $99.5 \%$ 1-butene/C4) [40]. However, no patent or further experimental work was disclosed.

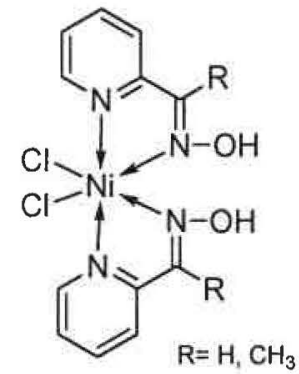

Figure 7: "Ni-oxime" complexes

\section{II.2- The SHOP process: Ni catalysts of type B}

Organometallic nickel complexes combining soft phosphorous and hard anionic oxygen atom in a chelate P-O ligand were described and first isolated by Keim in $1978[41,42]$. These catalysts are synthesized by mixing a phosphorus ylide (typically $\left.\mathrm{Ph}_{3} \mathrm{P}=\mathrm{C}(\mathrm{H})-\mathrm{Cl}=\mathrm{O}\right) \mathrm{Ph}$ ) in presence of $\mathrm{Ni}(\mathrm{COD})_{2}$ and a coordinating phosphine. They are isolable and suitable model of the SHOP type catalysts. It is worth mentioning that SHOP catalysis is operated in a biphasic system using 1,4-butanediol as the catalyst 
solvent. This process was the first commercial catalytic process to take benefit from two-phase, but non aqueous, liquid/liquid technology. The organometallic SHOP type catalysts have played a predominant role in the development of well-defined catalyst precursors for olefin oligomerization. To rationalize the ligand effects, it was suggested to break down the catalyst in two: a chelate part and an organo part [43] (Figure 8). In toluene, they produce alpha-olefins (under 50 bars of ethylene at $50^{\circ} \mathrm{C}$, activity up to $60000 \mathrm{~g}_{\mathrm{C} 2 \mathrm{H}} /\left(\mathrm{mol}_{\mathrm{Ni}} \cdot \mathrm{h}\right), 99 \%$ of the olefins are linear of which $98 \%$ are terminal) while in hexane polyethylene is formed. These catalysts are also capable of producing polyethylene when combined with a phosphine scavenger, which demonstrates their versatility [44]. Recently, the impact of a number of parameters on the catalytic properties of these complexes has been reported [45].

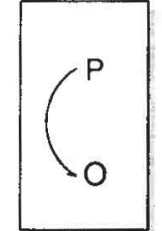

Chelate part
$\mathrm{Ni}$

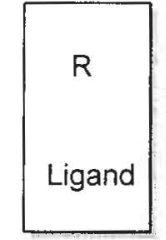

Organo part

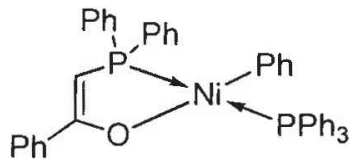<smiles></smiles>

Figure 8: Suitable organometallic model for SHOP catalyst (Type B)

Since we were interested in the short chain olefins, we have attempted to modify the electronic density at the nickel center in order to facilitate $\beta$-elimination during the growing chain. The strategy was to create an intramolecular hydrogen bonding between the enolate oxygen atom and an orthosubstituent on the aromatic ring of the $P, O$ chelate, with the aim to generate an electron withdrawing effect (Figure 9) $[46,47]$. We could demonstrate that the intramolecular hydrogen bonding allows a fine tuning of the selectivity of the complexes. In comparison to typical SHOP model complex, the alpha-olefin distribution significantly shifts towards the lower C4-C8 olefins of which $95-99 \%$ are linear $\alpha$-olefins, while the activity remaining unchanged.
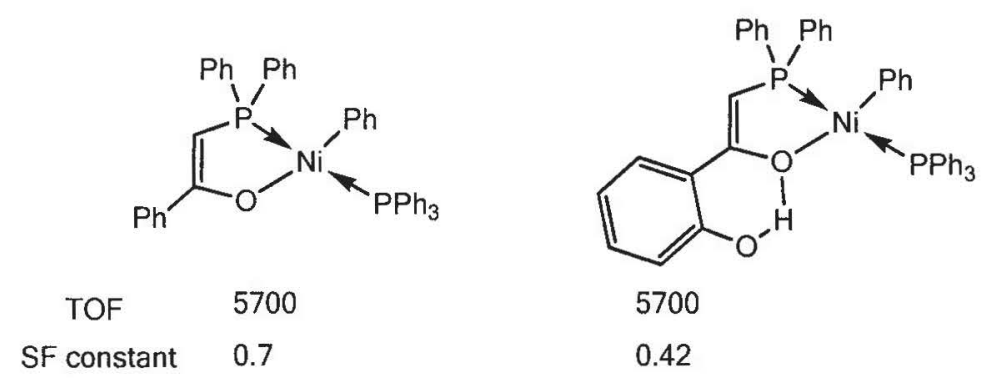

Figure 9 : Fine tuning of $\mathrm{P}-\mathrm{O}$ ligand with the occurrence of $\mathrm{H}$-bonding ( $\mathrm{SF}$ constant obtained in toluene, $0.10 \mathrm{mmol}$ catalyst, $60-95^{\circ} \mathrm{C}$, 60 bar ethylene, $90-300 \mathrm{~min}$ )

\section{Toward alternative anionic ligands}

During the following two decades, there was no significant progress in the design of different type of anionic ligands and corresponding neutral nickel catalysts. Just at the beginning of the century, the discovery of the versatile salicylaldiminato catalysts [48] open the way to investigations on neutral nickel complexes (type B). However, the studies have focused on the ethylene polymerization with the aim to control the microstructure of the polymer.

\section{III- CHROMIUM CATALYSTS FOR SELECTIVE ETHYLENE TRI- AND TERAMERIZATION}


The ability of chromium complexes to oligomerize selectively ethylene was discovered at Union carbide and reported in 1967 [49]. Manyik, Walker and Wilson observed the predominance of 1hexene in the liquid fraction during ethylene polymerization with chromium tris(2-ethylhexanoate) activated with partially hydrolyzed triisobutylaluminum, suggesting the presence of several active species and eventually mechanisms. This breakthrough triggered the search for selective trimerization and later tetramerization catalysts leading to industrial successes.

Although the first evidence for selectivity in 1-hexene with chromium-based catalysts was brought with a partially hydrolyzed alkylaluminum as activator, in other words, an aluminoxane, the first industrially relevant catalytic systems commercialized were developed with well-defined alkylaluminum and / or chloroalkylaluminum compounds. While Chevron Phillips Chemical Company LP (CPChem) reported the use of pyrrolide ligand in 1991 [50], IFPEN developed a catalytic composition based on an aryloxide ligand in 1998 (Figure 10) [51]. For both proprietary anionic ligands, their association to a chromium(III) precursor lead to selectivities in 1-hexene above $99 \%$ in the $\mathrm{C} 6$ fraction, affording a polymer grade co-monomer. CPChem implemented this technology through two joint ventures with Qatar Chemical Company Ltd. in Mesaieed (Qatar) and Saudi Polymers Company in Al Jubail (Saudi Arabia), producing $47000 \mathrm{t} / \mathrm{y}$ and $100000 \mathrm{t} / \mathrm{y}$, respectively [52]. In 2014, CPChem also announced the start-up of a 1-hexene production unit of $250000 \mathrm{t} / \mathrm{y}$ in Baytown, Texas (USA) [53]. In the meantime, Axens licensed in 2012, a production unit in Primorsk region (Russia) based on the 1-hexene IFPEN catalytic system [54]. In 2009, SABIC, Linde and the Rostock University disclosed a catalytic system formed by a chromium(III) precursor, $R_{2} P-N(R)-P(R)-$ $\mathrm{NHR}$ as ligand and triethylaluminum as activator for the selective ethylene trimerization to 1-hexene (Figure 10) [55]. The evaluation of such catalytic composition on the pilot plant scale should be ongoing [56].<smiles>[R]c1ccc([R])[nH]1</smiles><smiles>[R]c1c([R])c([R])c([2H])c([R])c1[R7]</smiles><smiles>[R]NP([R])N([R12])C</smiles>

Figure 10 : Ligand precursors for the selective ethylene trimerization processes

Although multiple coordination modes and reactivities toward the alkylaluminum and the chromium precursor used are possible, these three catalytic systems are believed to proceed via the wellknown metallacyclic mechanism to afford such selectivities in 1-hexene. Having a closer look to the side products formed is in line with such hypothesis, indeed, mainly decenes are produced, while octenes are kept to a minimum. Decenes are suggested to be formed by co-trimerization of 1-hexene with two molecules of ethylene through a chromacycloheptane [57]. Detailed studies of these systems and other examples of anionic monodentate or multidentate ligands in association with alkylaluminum have been described with in the literature and exhaustively reviewed $[6,58]$.

In 2002, BP Chemicals published highly active trimerization catalytic system comprising a chromium source and a neutral functionalized diphosphinoamine ligand $\left(>10^{6} \mathrm{~g}_{\mathrm{C} 2 \mathrm{H} 4} /\left(\mathrm{g}_{\mathrm{cr}} . \mathrm{h}\right)\right.$, Figure 11) when associated to methylaluminoxane $[59,60]$. Few years later, Sasol researchers showed that with a nonfunctionalized diphosphinoamine ligand, exceptionally high selectivities in 1-octene along with high activities could be obtained $(67,4$ wt. \% of 1-octene compared to all products formed, 2.7.10 $\left.\mathrm{g}_{\mathrm{C} 2 \mathrm{H} 4} /\left(\mathrm{g}_{\mathrm{Cr}} . \mathrm{h}\right)\right)[61,62]$. To satisfy the growing need in 1-octene, Sasol rapidly announced the construction in 2010 of a tetramerization unit producing $100000 \mathrm{t} / \mathrm{y}$ of 1-octene and 1-hexene in Lake Charles, Louisiana (US) [63]. The start-up of the unit was planned for late 2013, no further 
information are, however, accessible. Numerous diphosphinoamine and several other diphosphine ligands have also been reported in the literature for the selective tetramerization $[6,58]$.<smiles>COc1ccccc1P(c1ccccc1OC)N(C)P(c1ccccc1OC)c1ccccc1OC</smiles>

Figure 11 : Diphosphinoamine ligands for tri- and tetramerization of ethylene.

\section{IV- TITANIUM FOR SELECTIVE ETHYLENE DI- AND TRIMERIZATION}

Very early, titanium-based homogeneous catalysts have opened the door to selective ethylene dimerization to 1-butene [64,65]. In the mid-1980s, IFPEN and SABIC jointly developed the first commercially viable process for this reaction, the AlphaButol process [66]. Today, 30 AlphaButol units have been licensed for a cumulated 1-butene production capacity of $708 \mathrm{kt} / \mathrm{y}$, nearly $25 \%$ of the world's 1-butene consumption as co-monomer in polyethylene [67]. The catalytic system is based on a proprietary titanium(IV) precursor and an alkylaluminum co-catalyst which are both injected in the reactor to generate the active species $[1,4]$. Careful choice of this catalyst composition and reaction conditions lead to selectivity for 1-butene up to $93 \%$ (purity of 1-butene higher than $99.5 \%$ ). This field was later on the subject of interest for researchers in industry and academia. Nevertheless, if we except the initial statement of Chauvin et al. [68], few attempts to investigate the reaction mechanism induced by "Ti(OR) $)_{4} / \mathrm{AlR}_{3}$ " system were undertaken [69]. In its first proposal, Chauvin and co-workers identified titanacyclopentanes as possible intermediates for this reaction. Substituted titanacyclopentanes were then generated by reacting 1,4-dilithiobutanes with $\left[\mathrm{Ti}(\mathrm{OBu})_{4}\right]$ precursor. The nature of the hydrocarbons formed by thermal decomposition of these compounds and their comparison with the $\mathrm{C} 6$ by-products formed under real dimerization experiments, suggested successive formation in the catalytic cycle of metallacycle intermediates. Recently, several experimental [70] and theoretical studies [71] conducted by McGuinness and co-workers suggest that metallacycles are not likely responsible for the selective formation of dimers. According to these studies, a conventional Cossee-Arlman mechanism with very fast $\beta-H$ elimination could be the preferential route to explain the primary product 1-butene and the secondary reaction products. Despite its apparent simplicity, the mechanism involving " $\mathrm{Ti}(\mathrm{OR})_{4} / \mathrm{AlR}_{3}$ " system remains under discussion.

Titanium complexes also appeared in the last 10 years as good catalysts for the selective trimerization of ethylene to 1-hexene $[6,58]$. The first remarkable example was described in 2001 by Hessen and co-workers [72] with a system based on a cyclopentadienyl ligand bearing an aromatic group (Figure $12, \mathrm{I})$. At $30^{\circ} \mathrm{C}$ and 10 bar of ethylene, $\left[\left(\eta^{5} \mathrm{Cp}-\mathrm{CMe}_{2}-\mathrm{C}_{6} \mathrm{H}_{5}\right) \mathrm{TiCl} \mathrm{C}_{3}\right]$ upon activation with MAO was described as very active $\left(\approx 6.10^{6} \mathrm{gH}_{1}{ }^{2} / \mathrm{molTi} / \mathrm{h}\right.$ ) and selective for 1 -hexene production (86\% of $\mathrm{C} 6$ with more than $99 \%$ of 1-hexene). The thermal stability of the catalyst remains modest as increasing the reaction temperature to $80^{\circ} \mathrm{C}$ decreases the overall catalyst productivity and selectivity. The same authors carried out systematic studies based on structure performance relationship [73]. They demonstrated the delicate interplay of the steric and electronic properties of the ligands to reach catalysts presenting high activity and high selectivity for 1-hexene (examples II, III and IV, Figure 12). If none of these Cp-Ti(IV) complexes was operated at an industrial scale (to the best of our knowledge), their discovery represents a real breakthrough in the field of selective oligomerization using Ti complexes. 


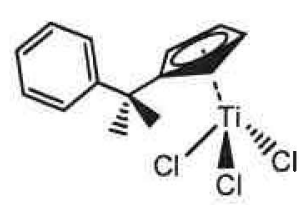

I

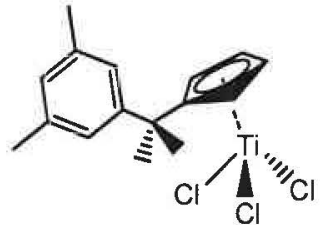

II

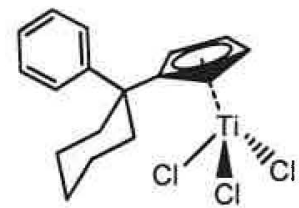

III

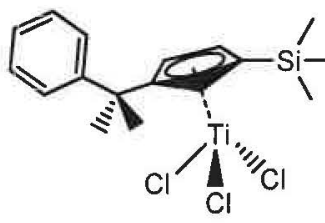

IV

Figure 12 : Examples of "Cp-Ti(IV)" complexes for selective ethylene trimerization

Detailed theoretical studies were also conducted in order to shed light on the mechanism $[74,75,76]$. After activation of the catalyst precursor $\left[\left(\eta^{5} \mathrm{Cp}-\mathrm{CMe}_{2}-\mathrm{C}_{6} \mathrm{H}_{5}\right) \mathrm{TiCl}_{3}\right]$ with MAO to generate a cationic $\mathrm{Ti}(I I)$ species, a $\mathrm{Ti}(\mathrm{II}) / \mathrm{Ti}(\mathrm{IV})$ metallacycle mechanism was predicted to operate. Mechanistic investigations also pointed out the critical role of the arene side arm of the $\mathrm{Cp}$ ligand. This part of the ligand has the capacity to modify its coordination mode to the titanium center from $\eta^{1}, \eta^{3}$ to $\eta^{6}$ [77]. DFT studies tried to rationalize selectivity for 1-hexene taking into account the capacity of the Rgroup grafted on the $\mathrm{Cp}$ ring to dissociate from the metal center [78]. Assuming that, whatever the nature of the R-group, the catalyst enters the metallacyclic mechanistic pathway, the authors have presented the dissociation energy of the arene group as a descriptor to explain 1-hexene selectivity. A model is proposed that predicts the formation of 1-hexene when the dissociation energy is larger than $15 \mathrm{kcal} / \mathrm{mol}$. In the case of smaller dissociation energies, multiple insertion reactions are likely to occur producing polyethylene as the major product.

Shortly after the discovery of $\left[\left(\eta^{5} \mathrm{Cp}-\mathrm{CMe}_{2}-\mathrm{C}_{6} \mathrm{H}_{5}\right) \mathrm{TiCl}_{3}\right] / \mathrm{MAO}$ system, substitution of the arene group by chelating heteroatoms was proposed. In 2003, Huang et al. replaced the pendant arene with a thienyl group (Figure 13, V) [79]. Selectivity for 1-hexene appeared at a very high level (84\%) with nevertheless apparent poor activity compared with the arene analogue. Substitution of the sulfur by a more coordinating ether group (Figure 13, VI) renders the system quite inactive [80]. The same group has recently proposed a new evolution of this catalyst by introducing indenyl group instead of cyclopentadienyl [81]. This evolution is assumed by the authors to improve the activity compared with the corresponding cyclopentadienyl complex (Figure 13, VII).

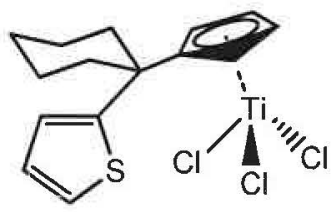

$\checkmark$

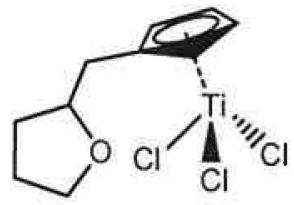

VI

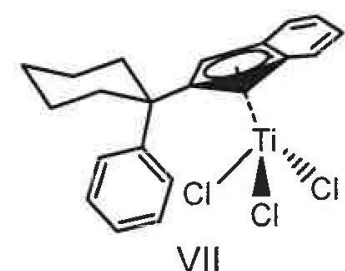

VII

Figure 13 : Functionalized "Cp-Ti(IV)" complexes

Viewing these first examples, the ligand hemilability [82] appeared as a key parameter to promote selective ethylene oligomerization rather than polymerization. Owing to the expected reversible coordination of the pendant group, such ligands could stabilize highly reactive electrophilic metal centers until the substrate coordinates and replaces the pendant group. Introduced as alternative to cyclopentadienyl ligands for the development of post metallocenes group 4 complexes [83], aryloxybased ligands have also raised a great deal of interest in that field, partly due to their versatile coordination mode and their potential to bring 5 electrons to the metal center (Figure 14) $[84,85]$. 
<smiles>[R]C([M])([M])O</smiles>

bridging $\mu^{3}$<smiles>[M]O[O]</smiles>

$\mathrm{M}-\mathrm{O}-\mathrm{R}=109^{\circ}$<smiles>[M]OC([R])[R]</smiles>

bridging $\mu^{2}$<smiles>[R][O+]1CC1</smiles>

$M-O-R=120^{\circ}$<smiles>[R]O[M]</smiles>

terminal<smiles>[R]OC1CCC([M])O1</smiles>

$M-O-R=180^{\circ}$

Figure 14 : Coordination modes of aryloxy type ligands

In 2009, Magna and co-workers at IFPEN described several functionalized aryloxy-Ti(IV) complexes of general formula [(ArO-L)Ti(O'Pr $)_{3}$ ], as precursors for selective ethylene oligomerization [86]. Depending on the structure of the aryloxy, mononuclear as well as binuclear complexes were obtained (Figure 15). The hemilabile behavior of the aryloxy ligand in IX (Figure 15) resulting from reversible coordination of the $-\mathrm{NMe}_{2}$ arm was demonstrated by variable-temperature ${ }^{1} \mathrm{H} N M R$ spectroscopy. Upon activation with MAO these catalysts appeared poorly active with respect to ethylene with a selectivity oriented towards polymers (>95\%) [87]. However, when activated with AlEt $_{3}$ ( 3 eq./Ti) at 20 bar and $60{ }^{\circ} \mathrm{C}$, these complexes exhibited interesting activity (up to $2100 \mathrm{~g} / \mathrm{gTi} / \mathrm{h}$ ) for the selective dimerization of ethylene to 1-butene ( $92 \%$ butenes; $99^{+} \% 1$-butene). Noticeable differences in catalyst activity were observed when the hemilabile part was modified. This work was extended later to functionalized bis(aryloxy)-Ti(IV) complexes of general formula [(ArO$\mathrm{L}_{2} \mathrm{Ti}\left(\mathrm{O}^{\prime} \mathrm{Pr}\right)_{2}$ ] with the same catalytic tendencies [88]. In parallel with this study, investigations on functionalized imido Ti(IV) complexes were also undertaken [89]. Upon activation with MAO, all the catalysts evaluated appeared selective for ethylene polymerization.<smiles></smiles>

VIII<smiles>CCc1cc(C)cc(CC(C)C)c1O[Te](OC(C)C)(OC(C)C)C(C)C</smiles>

IX<smiles>COCc1cc(C)cc(C(C)(C)C)c1O[P](OC)(OC)(OC)(OC)Oc1c(C)cc(C)cc1C(C)(C)C</smiles>

$x$

Figure 15: Examples of $\left[\left(\mathrm{ArO}-\mathrm{L}_{n} \mathrm{Ti}\left(\mathrm{O}^{\mathrm{P}} \mathrm{Pr}\right)_{4-n}\right]\right.$ for selective ethylene dimerization

In the field of selective ethylene trimerization using titanium catalyst, another very recent breakthrough is the work published by Fujita and Mitsui company $[90,91]$. Since many years, Fujita and co-workers developed a ligand oriented research with the use of phenoxy-imines type ligand in group 4 polymerization (named $\mathrm{Fl}$ systems) [92]. In the course of their investigations, they found that very specific phenol imine ligand (Figure 16) can convert ethylene into 1-Hexene with high selectivity 
and quite high productivity. To the best of our knowledge, this system has been implemented at the industrial scale at Ishihara (Japan) [2]. From this study, and the results published in the corresponding patent [93], it emerged that the nature of the bridging spacer linked to the hemilabile ether group is crucial for determining the selectivity for 1-hexene. Variation of 1-hexene selectivity from selected examples extracted from [93] is presented in Figure 16.

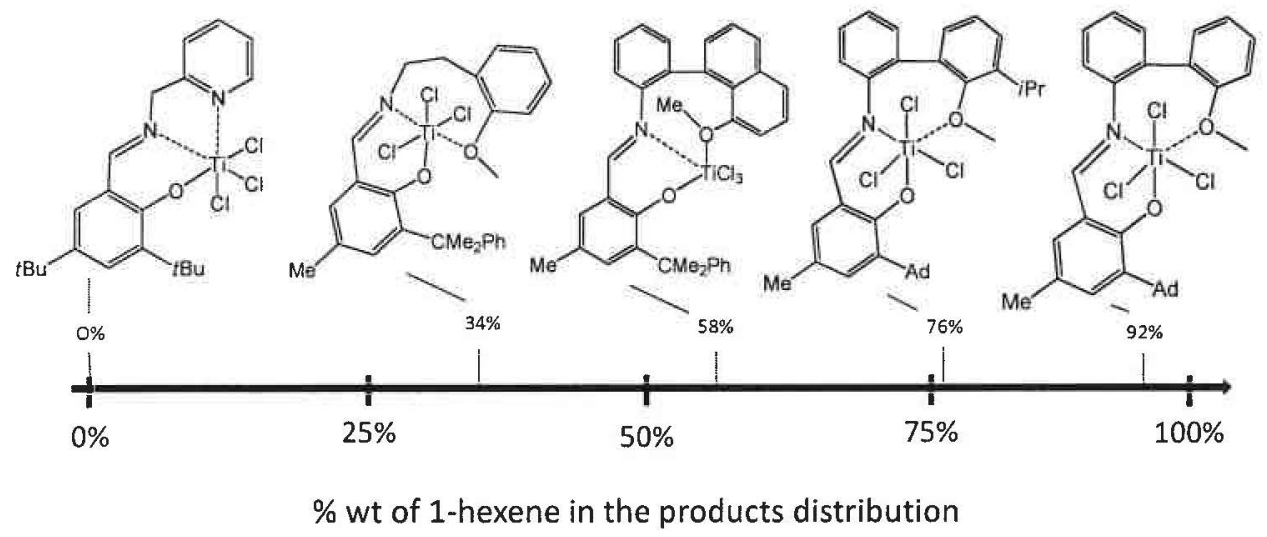

Figure 16 : From polymerization to selective ethylene trimerization with tridentate Fl-type catalysts

The authors proposed that the reaction mechanism goes through a metallacycle formation from a cationic $\mathrm{Ti}(\mathrm{II})$ intermediate [90]. Interestingly, catalyst productivity shows a second-order dependence on ethylene pressure, suggesting that the rate-determining step is the formation of the Ti(IV) metallacyclopentane intermediate. Along the same line, Bercaw et al. recently reported the synthesis and characterization of the cationic $\left[\mathrm{FI}-\mathrm{TiMe}_{2}\right]^{+}\left[\mathrm{MeB}\left(\mathrm{C}_{6} \mathrm{~F}_{5}\right)_{3}\right]^{-}$complex generated from the most selective Fujita's pre-catalyst. This complex also proved to be an effective pre-catalyst for the ethylene trimerization reaction $[94,95]$.

More recently, McGuinness et al. published titanium catalysts, obtained by combination of phenoxyimine moiety from the $\mathrm{Fl}$ catalysts and the arene group characteristic of Hessen catalysts [96]. A series of Ti(IV)-catalysts were prepared and tested for the ethylene oligomerization and polymerization reactions (Figure 17). Predominantly these catalysts formed polyethylene with small amount of 1-hexene in some cases.
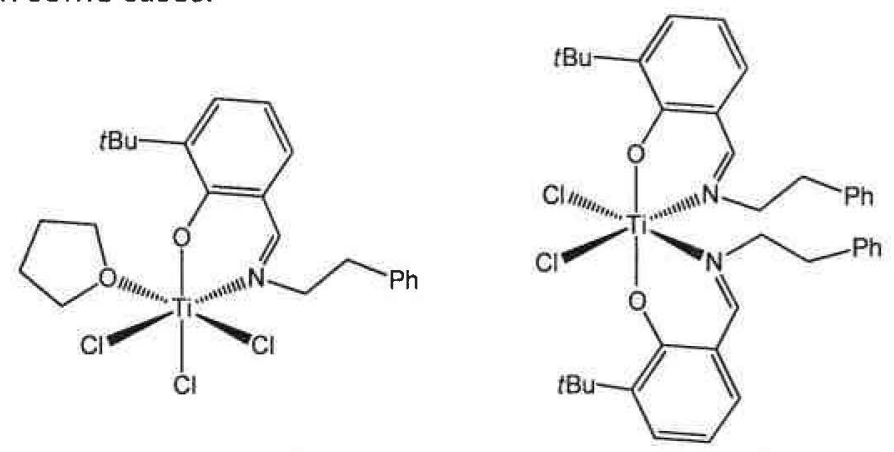

Figure 17 : Examples of functionalized aryloxy-imine Ti(IV) complexes

In another publication McGuinness et al. reported the investigations of analogues of Fujita titanium catalysts towards ethylene oligomerization reaction [97]. From all the catalysts considered in this study (Figure 18), complex bearing a thioether as donor group gave the best results in term of selectivity for 1 -hexene, however polyethylene was still the main product of the reaction. 

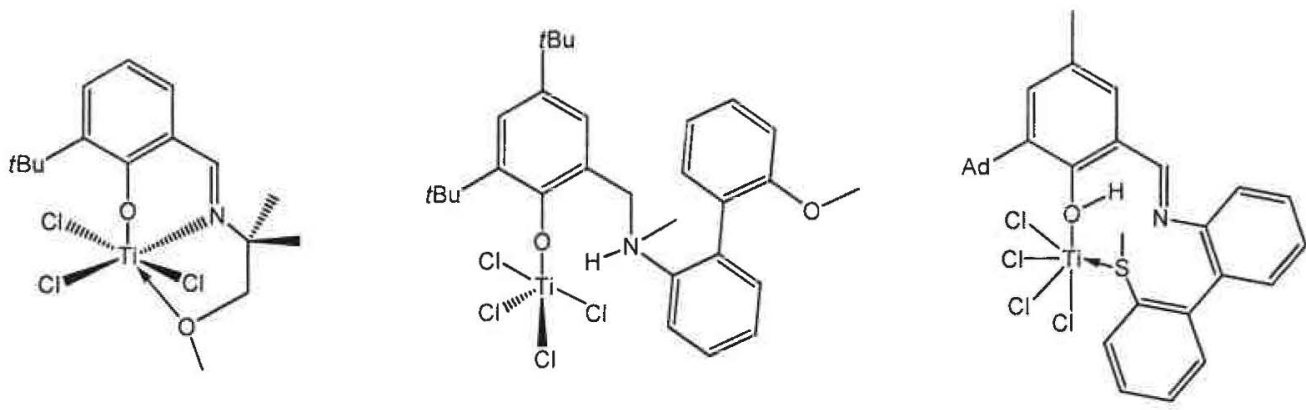

Figure 18 : Fujita's analogues for ethylene trimerization and polymerization

\section{V- ZIRCONIUM CATALYSTS FOR UNSELECTIVE ETHYLENE OLIGOMERIZATION}

Along with group 4 complexes, zirconium-based systems appeared very early as efficient catalysts for olefins polymerization [83]. Cyclopentadienyl-based complexes, once activated with MAO, are among the most active and selective zirconium catalysts for both ethylene and propylene polymerization. In comparison to this literature, examples of zirconium catalysts for ethylene oligomerization remains scarce. Processes operating with this metal were nevertheless industrially developed to produce mainly $\mathrm{C} 4$ to $\mathrm{C} 12$ olefins in order to maximize the amount of $\alpha$-olefins in the co-monomer range. Processes developed by SABIC-Linde (AlphaSablin [56]), Idemitsu [2] or IFPEN/Axens (AlphaSelect $[1,4])$ are by far the most widely described. These processes operate in the liquid phase using proprietary soluble $\mathrm{Zr}$-based catalytic systems activated in situ by an alkylaluminum alkyl co-catalyst, affording ethylene oligomers having a Schulz-Flory type distribution. The propensity of zirconium to modulate product distribution makes processes based on this metal versatile and useful to access specific $\alpha$-olefins distribution (Table 1).

The role of the non-MAO aluminum co-catalyst was described as a key parameter to control the product distributions. Detailed study on this aspect was published in 2002 by Shiraki and co-workers [98]. He describes particularly the role of organic additives on the performances of the three components " $\mathrm{ZrCl}_{4}$-TEA-EASC" oligomerization catalyst. The effect of organic additives was discussed on the basis of their ionization potential (IP) and electron density (ED). As exemplified, additives with small IP (tetrahydrothiophene) improve the purity of the $\alpha$-olefins. Heterocompounds additives presenting large electron density (tetrahydrofurane) have detrimental effect on the polymer amount produced.

Up to now, attempts to selectively oligomerize ethylene to 1-butene, 1-hexene or 1-octene with zirconium catalysts were quite unsuccessfull [7]. Shortly after the discovery of Cp-based titanium catalysts for selective trimerization of ethylene to 1-hexene [72], theoretical calculations were performed to evaluate the potential of zirconium and hafnium analogs to selectively produce 1hexene and/or 1-octene $[99,100,101]$. Calculations predict 1-hexene as the major product for zirconium catalysts. Experimental investigations performed later by McGuinness et al. did not confirmed these predictions as all the zirconium-based catalysts evaluated produced only polyethylene [102].

\section{VI- IRON BASED CATALYSTS FOR UNSELECTIVE ETHYLENE OLIGOMERIZATION}

The ability of iron catalysts to form carbon-carbon bonds from unsaturated compounds was initially reported by Hata in the 1960s, focusing on dienes as butadiene or isoprene [103,104,105]. Mainly monodentate donor ligands as $\mathrm{PPh}_{3}$ have been investigated in Ziegler-Natta type systems comprising

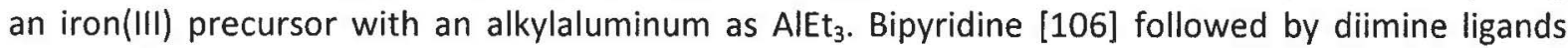
$[107,108]$ were then described by Misono and tom Dieck, respectively, for the cyclodimerization of butadiene to cyclooctadiene and vinylcycloohexene. All these homogeneous systems are suggested 
to lead to an iron(0) active species as co-catalysts having reductive properties are mainly used such as $\mathrm{AlEt}_{3}$, or Grignard reagents.

Until the late 1990s, the reactivity of iron towards mono-olefins was not reported to the best of our knowledge. The breakthrough independently reported by the groups of Brookhart [109] and Gibson [110] triggered the "iron age" for the transformation of olefins, especially the oligomerization and polymerization of ethylene. This surprising reactivity arose from the fine association of a tridentate bis(imino)pyridine ligand with an iron(II) pre-catalysts activated by a methylaluminoxane, leading to exceptional activities along with an excellent alpha selectivity for the olefins produced (Figure 19). Moreover, the easy tuning of the ligand structure led to a broad range of products from low molecular weight linear alpha olefins to high molecular weight linear polyethylenes. The technology was commercialized under the trademark of Versipol by DuPont which offers the technology for licensing [111] for high density polyethylene production and a range of olefin oligomers (Schulz-Flory distribution). However, no commercial unit was announced yet. It seems that operating this kind of highly active catalytic system is still challenging and involve the development of novel approach to resolve the technical challenge [112]. Detailed recent reviews cover all the complex modifications that have been studied $[113,114]$, but also bring to the foreground several limitations of the ironcatalyzed ethylene oligomerization. While the most active systems are based on an iron(II) precursors bearing a tridentate neutral ligand and activated by a methylaluminoxane, they present by-product and stability issues, particularly in temperature. Considering the different iron(II) precatalysts reported in the literature, the donor-functionalized diimine- and phenantroline-based complexes appear among the most promising systems when activated by (modified) methylaluminoxane, leading to wax- or polymer-free distributions of oligomers (Figure 19) $[115,116]$.
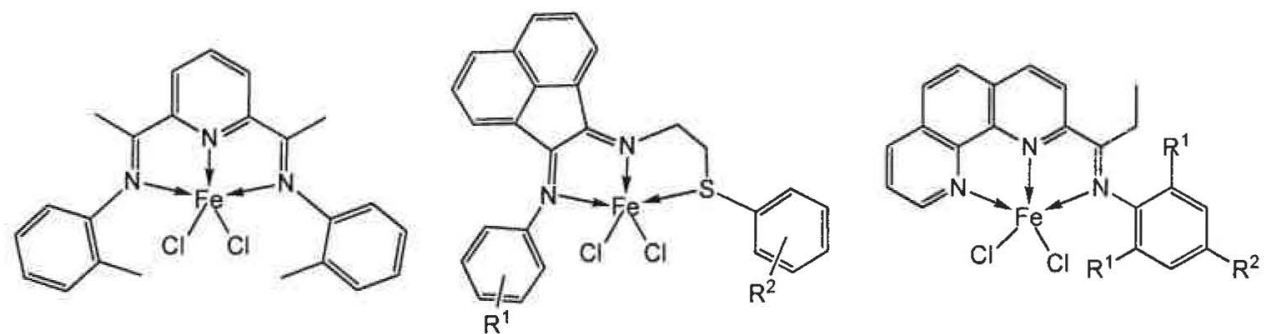

Figure 19 : Bis(imino)pyridine, donor-functionalized diimine- and phenanthroline-based precursors for iron-catalyzed ethylene oligomerization.

In comparison, bidentate $\mathrm{N}, \mathrm{N}$ neutral ligands as pyridine-imine [117] or quinoline-imine [118] on iron(II) precursors have also been investigated [113] and generally led to lowly active or inactive catalysts towards ethylene in presence of MAO (Figure 20).
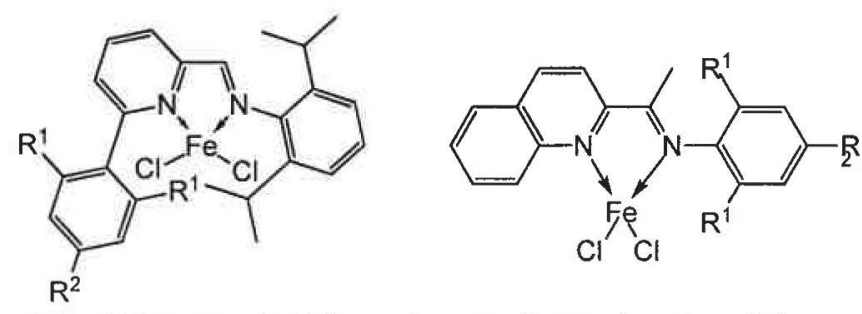

Figure 20 : Bidentate $\mathrm{N}, \mathrm{N}$ ligands coordinated on iron(II) precursor.

IFPEN was interested in the development of mono-anionic tridentate ligand and obtained $\mathrm{N}, \mathrm{NH}, \mathrm{N}$ ligands based on a 1,2-dihydro-1,10-phenanthroline scaffold from condensation of 2-acetylpyridine with 8-aminoquinoline derivatives [119]. In presence of a base as BuLi, these ligands were coordinated on an iron(III) precursor leading to a pseudo-square pyramidal coordination geometry (Figure 21) [120]. While little to no activity was observed in presence of MAO at $40^{\circ} \mathrm{C}$ and 30 bar of 
ethylene, at $80^{\circ} \mathrm{C}$, a steady ethylene uptake was noticed over 2 hours. Ethylene was transformed to short-chain oligomers with up to $63 \mathrm{wt}$. \% of butenes compared to all products formed. Polymer production (12 wt. \% / all products) was also observed accompanying the product distribution that may suggest multiple active species. The iron(III) complex coordinated by the tridentate ligand under its neutral form and the corresponding iron(II) complexes appeared to be inactive under ethylene in presence of MAO, highlighting the synergistic combination of the anionic ligand with the oxidation state of the iron precursor.

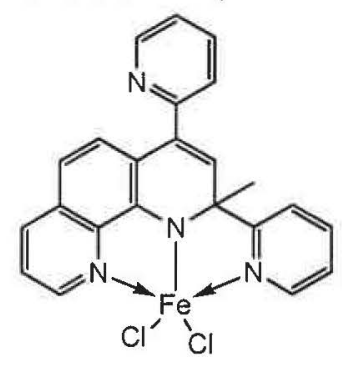

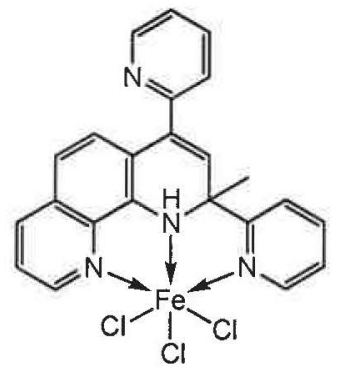

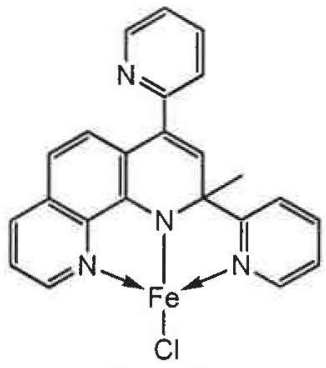<smiles>CC12C=C(c3ccccn3)c3ccc4cccn(c3-4)N1C1(C)N3CC=CC=C3C21Cl</smiles>

Figure 21 : Anionic and neutral N,N,N ligands on iron(III) and iron(II) precursors.

Starting from the iron(II) precursor bearing the $\mathrm{N}, \mathrm{NH}, \mathrm{N}$ ligand, we investigated an oxidative path to access iron(III) pre-catalysts. In solution in acetonitrile and with bubbling $\mathrm{O}_{2}$, the pink solution containing the iron(II) complex progressively turned to a dark purple mixture [121]. The characterization by $I R$ of the complex formed showed the absence of proton. By analogy, we performed the same oxidation reaction on an iron(II) 1,3-bis(2'-pyridylimino)isoindoline complex and the $\mu$-oxo-bridged diiron(III) complex could be isolated and characterized by XRD (Scheme 6 ). Such species has already been described although the synthesis was performed with an equimolar amount of the ligand and $\mathrm{FeCl}_{3} \cdot 6 \mathrm{H}_{2} \mathrm{O}$ [122].

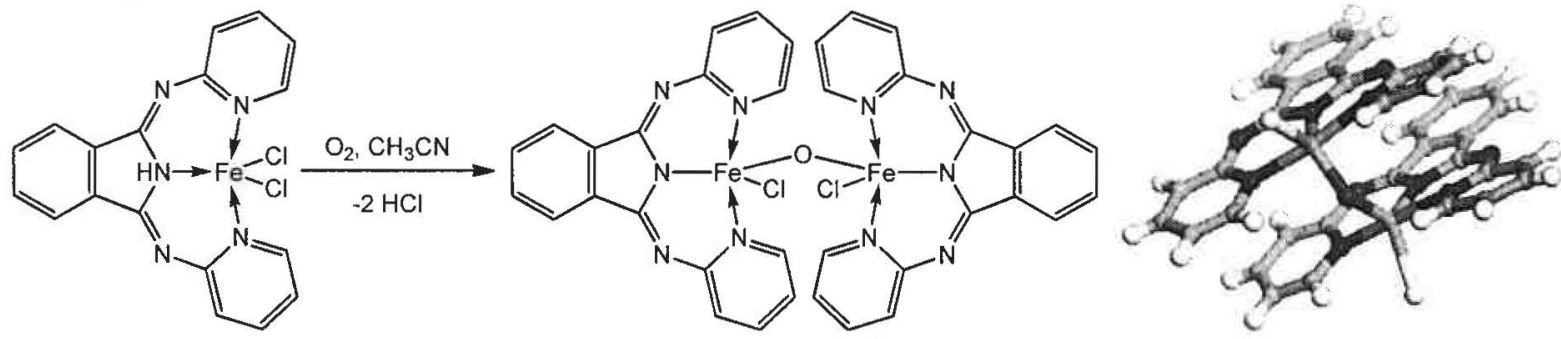

Scheme 6 : Synthesis of $\mu$-oxo-bridged diiron(III) complex

The proposed $\mu$-oxo-bridged diiron(III) bearing a 1,2-dihydro-1,10-phenanthroline (Figure 22) obtained by oxidation could transform ethylene upon $\mathrm{MAO}$ activation at $80^{\circ} \mathrm{C}$ and 30 bar, affording a $\mathrm{C}_{4}$ to $\mathrm{C}_{12}$ distribution of oligomers along with polymer (11 wt. \%) [123].

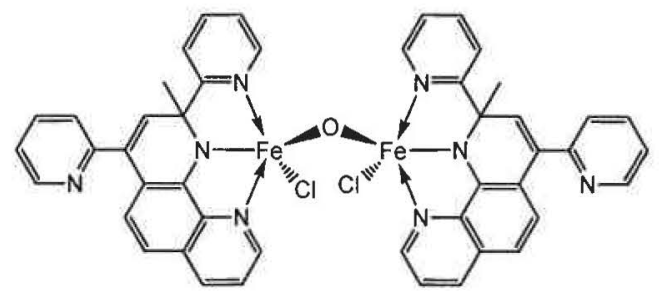

Figure 22 Proposed $\mu$-oxo-bridged diiron(III) complex.

The nature of the active species formed by MAO activation of iron complexes remains a central scientific question. In a recent report, we disclosed the use of a well-defined aluminum-based co- 
catalyst [PhOAIMe $]_{2}$ for the iron-catalyzed ethylene oligomerization (Figure 23) [124]. Considering that the cationic alkyl iron(II) species is formed in the activation process, we highlighted in this experimental and theoretical study the mechanisms favoring or inhibiting ethylene oligomerization. A weak interaction in the ion pair is preferred as observed for the well-defined co-catalyst and a representative MAO model leading to active catalyst, whereas trivalent aluminum sites as in $\mathrm{AlMe}_{3}$ may favor the adduct formation leading to catalyst inactivity. Recently, we extended this approach to diol and bis(phenol) compound. We observed that in association with $\mathrm{AlMe}_{3}$, they form well-defined tri-aluminum complexes as described by Ziemkowska (Figure 23) $[125,126]$. In presence of iron(II) or iron(III) complexes, active catalysts are generated affording Schulz-Flory distribution of oligomers comparable to the ones observed with MAO.
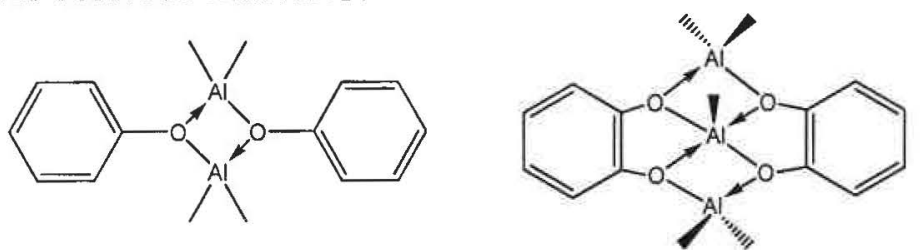

Figure 23 : Well-defined co-catalysts for the iron-catalyzed oligo

\section{VII- TUNGTEN BASED CATALYSTS FOR SELECTIVE ETHYLENE DIMERIZATION}

Tungsten-based catalysts were described since the 1960 s as active for the metathesis of olefins [127]. Interestingly, Menapace and coworkers from Goodyear showed in 1975 that for $\mathrm{WCl}_{6}$ in presence of aniline a reaction switch from metathesis to dimerization of 2-pentene is observed depending on the Al/W ratio [128]. Applied to ethylene, excellent selectivities in 1-butene $>98 \%$ compared to all products formed) were afforded by refluxing $\mathrm{WCl}_{6}$ in presence of 2 equivalents of aniline in chlorobenzene and further activated by $\mathrm{Et}_{2} \mathrm{AlCl}(\mathrm{Al} / \mathrm{W}=80)$ at 34 bar and $40^{\circ} \mathrm{C}$ [129]. More sterically hindered 2,6-dimethylaniline introduced in similar conditions as described above led to significant enhancement of the activity with up to $2.8 .10^{4} \mathrm{~g}_{\mathrm{C} 2 \mathrm{H} 4} /\left(\mathrm{gw}_{\mathrm{w}} \mathrm{h}\right)$ while maintaining the 1-butene selectivity to $98 \%$ [130]. In the meantime, Goodyear filled several patents related to propylene dimerization describing catalyst additives. Prior to the introduction of the aniline compound, the tungsten precursor is mixed with an carboxylic acid [131], a phenol [132] or a diketone [133] molecule leading to active catalysts in association with ethylaluminum sesquichloride (EASC) for example, however no peculiar selectivity is observed.

With such approach, uncertainties remain regarding the nature of the catalyst precursor, hampering comprehension and to formulate hypothesis on the activation step and the catalytic mechanism in operation. Starting from $\mathrm{WOCl}_{4}$, IFPEN synthesized and isolated the mono-imido complex $[(2,6-$ $\mathrm{Me}_{2} \mathrm{C}_{6} \mathrm{H}_{3}$ ) N=WCl ] (Figure 24) [134]. Moderate activities were observed over more than 4 hours (up to $\left.3.4 .10^{3} \mathrm{~g}_{\mathrm{C} 2 \mathrm{H} 4} /\left(\mathrm{g}_{\mathrm{w}} \cdot \mathrm{h}\right)\right)$ affording good selectivity for ethylene dimerization at $40^{\circ} \mathrm{C}$ and at 60 bar when activated by $\mathrm{Et}_{2} \mathrm{AlCl}$ or $\mathrm{EtAlCl}_{2}$ at a Al/W molar ratio of 40 . Two catalytic mechanisms may be considered for high selectivity in 1-butene. They may be initiated whether by the formation of metal alkyl species leading to a Cossee-Arlman type mechanism or by the reduction of the tungsten precursor followed by the concerted coupling of two molecules of ethylene. Thus IFPEN prepared and isolated the low oxidation state imido complex, stabilized by $\mathrm{PMe}_{3},\left[\mathrm{PhN}=\mathrm{WCl}_{2}\left(\mathrm{PMe}_{3}\right)_{3}\right]$ (Figure 24), inactive in presence of ethylene alone but that led to ethylene dimerization in presence of 4.5 equivalents of $\mathrm{AlCl}_{3}$, suggesting that the metallacyclic mechanism may be in play. 

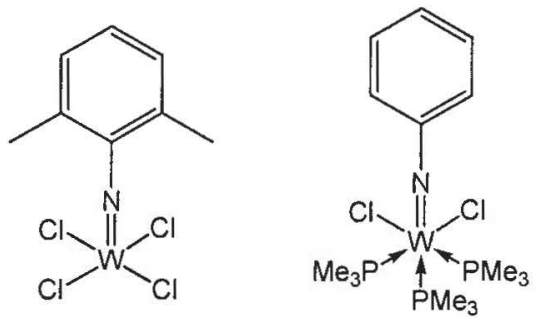

Figure 24 : Well-defined tungsten precursors for ethylene dimerization.

This hypothesis was supported by a DFT study from Tobisch who described a mono-imido tungsten complex as an effective catalyst when chelated by a Lewis acid [135]. The bis(imido) tungsten compound associated to a Lewis acid was also investigated and may be considered as an efficient system for olefin dimerization [136]. This study highlighted as well that one imido may be released leading to the active mono-imido tungsten catalyst. To confirm or infirm the bis(imido) tungsten complex activity, Hanton, Dyer et al. reported, few years later, the synthesis of well-defined bimetallic complexes $\left[\mathrm{PhN}=\mathrm{WMe}_{2}(=\mathrm{N}(\mathrm{Ph}) \mathrm{AlMe}(\mathrm{X})(\mu-\mathrm{Cl}))\right]$ (with $\mathrm{X}=\mathrm{Cl}$ or Me, Figure 25) [137]. However, these complexes proved to be inactive in presence of ethylene. The in situ generated catalyst although ill-defined remains the most efficient system to promote olefin dimerization. A detailed catalytic study from Sasol led to selectivity above $99 \%$ for dimerization of 1-pentene to 1nonene depending on the catalyst components and their stoichiometry [138]. Having a closer look to the products formed, the authors proposed that the Cossee-Arlman mechanism is effective, supported by a $\mathrm{C}_{2} \mathrm{H}_{4} / \mathrm{C}_{2} \mathrm{D}_{4}$ co-dimerization experiment leading to full isotopic scrambling. It should however be noted that a second order dependence on substrate is also described that still questions the mechanism to consider. Although a series of patents was published in 2007 by Sasol [139], relative to olefin dimerization for methyl branched compounds production, no press release or announcement for a process commercialization was published.

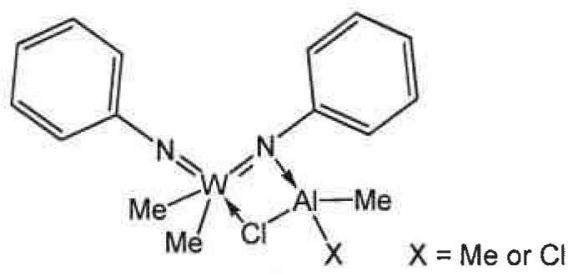

Figure 25 : Bimetallic bis(imido)complex.

\section{VIII- CONCLUSION}

Since its discovery 60 years ago, the transition metal homogeneous catalyzed oligomerization of light olefins has remained a topic of prime importance in academia and industry. The oligomerization of ethylene to Linear Alpha Olefins is one of the main growing area of homogeneous catalysis owing to the increasing market demand for LAO, most notably as co-monomers for PE. It is one of the applied catalysis area that has seen the emergence of the main scientific breakthrough and developments of novel industrial processes such as for the first time the ethylene tetramerization. One of the outstanding feature of oligomerization is that many transition metals, representative of group 4 to group 10, have shown their ability to be effective catalyst. Despite an abundant literature, only some of them display exceptional activity and selectivity, highlighting that selective ethylene dimerization, trimerization and tetramerization are far to be trivial and well-understood reactions. This opens avenues for cutting edge research of a broad scientific community. Moreover, the demand for the selective formation of short chain alpha olefins poses challenges at the interface of different science: coordination, organometallic chemistry, catalysis, modeling and process design....

From the early days, IFPEN has recognized the potential of oligomerization and followed it from basic research to developments. Armed with this experience and in the light of the industrial 
achievements, we attempted in this report to show, with selected examples, the specificity and deficiency of each metal and the corresponding catalytic systems. For example, the same metal can react via different mechanisms and drive the transformation to polymerization or oligomerization depending on operating conditions or co-catalyst applied. The challenge continued to a greater control of the selectivity and to the possibility to design "on purpose processes". The right combination of metal-ligand-activator remains the key of the discovery even if the development of new ligands has been essential. There is no single rule for ligand design and subtle changes can switch the reaction outcome. One may anticipate that in the forthcoming years, studies on the fundamental and applied aspects, will allow the finding of new oligomerization catalyst generation with improved efficiency and sustainability.

1. Forestiere A, Olivier-Bourbigou H, Saussine L (2009) Oil Gas Sci Technol Rev IFP 64:649-667.

2. IHS Chemicals, Chemical Economics Handbook:Linear alpha-Olefins, August 2013.

3. Armor JN (2014) Cat Today 236:171-178.

4. Olivier-Bourbigou H, Forestiere A, Saussine L, Magna L, Favre F, Hugues F (2010) Oil Gas Eur Mag 2:97-102.

5. Hydrocarbon Processing (2012) February 28. http://www.axens.net/product/technology-

licensing/11010/alphahexol.html

6. McGuinness DS, (2011) Chem Rev 111:2321-2341.

7. Skupinska J (1991) Chem Rev 91:613-648.

8. Al-Jarallah AM, Anabtawi JA, Siddiqui MAB, Aitani AM, Al-Sa'doun AW (1992) Cat Today 14:1-124.

9. Speiser F, Braunstein P, Saussine L (2005) Acc Chem Res 38:784-793.

10. Andes C, Harkins SB, Murtuza S, Oyler O, Sen A (2001) J Am Chem Soc 123:7423-7424.

11. Zhang S, Nomura K (2010) J Am Chem Soc 132:4960-4965.

12. Olivier-Bourbigou H, Magna L (2012) Applied Homogeneous Catalysis with Organometallic compounds, A Comprehensive Handbook in Three Volumes "Dimerization and selective oligomerization - Selected examples of industrial applications", Cornils B, Herrmann WA, Beller M, Paciello R Eds, Wiley-VCH.

13. Wilke G (2003) Angew Chem Int Ed 42:5000-5008.

14. Gao R, Sun WH, Redshaw C (2013) Catal Sci Technol 3:1172-1179.

15. Wilke G, Bogdanovic B, Hardt P, Heimbach O, Kroner W, Oberkirch W, Tanaka K, Steinrucke E, Walter D, Aimmerman $\mathrm{H}$ (1966) Angew Chem Int Ed 5:151-164.

16. Convers A, Commereuc D, Torck B (1994) Revue de l'Institut Francais du Petrole 49:437-51.

17. Gale RJ, Gilbert B, Osteryoung RA (1978) Inorg Chem 17:2728-2729.

18. Chauvin Y, Gilbert B, Guibard I (1990) J Chem Soc Chem Commun 1715-1716.

19. Chauvin Y, Di Marco-Van Tiggelen F, Olivier H (1993) J Chem Soc Dalton Trans 1009-1011.

20. Olivier-Bourbigou H, Favre F, Forestière A, Hugues F (2009) Handbook of Green Chemistry - Green Catalysis, Anastas P Ed., in Homogeneous Catalysis, Crabtree R Ed., Vol 1, p101-126, Wiley-VCH Weinheim.

21. Forestiere A, Favre $F(2005)$ in Multiphase Homogeneous Catalysis, Cornils B. Ed. Vol2:547-560, Wiley-VCH.

22. Anonymous (1990) Chem Britain 26:400.

23. Sato H, Tojima H, Ikimi K (1999) J Mol Catal A Chem 144:285-293.

24. Chauvin Y, Einloft S, Olivier H (1995) Ind Eng Chem Res 34 :114-115.

25. Carter C (1980) US 4242531, (1985) US4538018.

26. Boulens P, Lutz M, Jeanneau E, Olivier-Bourbigou H, Reek JNH, Breuil PAR (2014) Eur J Inorg Chem 3754-

3762.

27. Olivier-Bourbigou H, Lecocq V (2003) Studies in Surface Science and Catalysis 145:55-60.

28. Lecocq V, Olivier-bourbigou H(2007) Oil \& Gas SciTech Rev IFP 62:761-773.

29. McGuinness DS, Mueller W, Wasserscheid P, Cavell KJ, Skelton BW, White AH, Englert W (2002)

Organometallics 21:175-181.

30. Olivier-Bourbigou H, Commereuc D, Harry S (2001) US 6576724 B2; US 6667669.

31. Clement ND, Cavell KJ (2004) Angew Chem Int Ed 43:3845-3847.

32. Lavallo V, Canac Y, Präsang C, Donnadieu B, Bertrand G (2005) Angew Chem Int Ed 44 :5705-5709.

33. Jazzar R, Dewhurst RD, Bourg JP, Donnadieu B, Bertrand G (2007) Angew Chem Int Ed 46:2899-2902.

34. Mignani G (2008) WO 125568.

35. IFPEN, unpublished results.

36. IFPEN, unpublished results.

37. Hameury S, de Frémont $P$, Breuil PAR, Olivier-Bourbigou H, Braunstein P (2014) Dalton Trans 43:4700-4710. 
38. Svejda SA, Brookhart M (1999) Organometallics $18: 65-74$.

39. Boudier A, Breuil PAR, Magna L, Olivier-Bourbigou H, Braunstein P (2012) J Organomet Chem 718:31-37 and references therein.

40. Mukherjee S, Patel BA, Bhaduri S (2009) Organometallics 28:3074-3078.

41. Keim W, Kowaldt F H, Goddard, Krüger R C (1978) Angew Chem Int Ed 17:466-467.

42. Keim W (2013) Angew Chem Int Ed 52:12492-12496.

43. Keim W (1990) Angew Chem Int Ed 29:235-244.

44. Klabunde U, Ittel SD (1987) J Mol Catal 41:123-134.

45. Kuhn P, Semeril D, Matt D, Chetcuti MJ, Lutz P (2007) Dalton Trans 515-528.

46. Braunstein $P$, Chauvin Y, Mercier S, Saussine L (2005) C R Chimie 8:31-38.

47. Braunstein P, Chauvin Y, Mercier S, Saussine L, De Cian, Fischer J (1994) J Chem Soc Chem Commun 22032204.

48. Younkin TR, Connor EF, Henderson JI, Friedrich SK, Grubbs RH, Bansleben DA (2000) Science 287:460-462.

49. Manyik RM, Walker WE, Wilson TP (1967) US Patent 3300458.

50. Reagan WK (1991) EP Patent 0417477.

51. Commereuc DC, Drochon S, Saussine L (1998) US Patent 6031145.

52. Nexant PERP 2011S11. Developments in LAO Comonomer Technologies for Polyethylene. May 2012.

53. http://www.cpchem.com/en-us/news/Pages/Chevron-Phillips-Chemical-Announces-Mechanical-

Completion-and-Start-Up-of-World\%27s-Largest-1-Hexene-Plant.aspx

54. http://www.axens.net/news-and-events/news/170/far-east-petrochemical-company-has-selected-axenstechnologies-for-the-production-of-1-butene-and-1-hexene.html

55. Fritz PM, Bölt H, Wöhl A, Müller W, Winkler F, Wellenhofer A, Rosenthal U, Hapke M, Peulecke N, Al-Hazmi MH, Aliyev VO, Mosa FM (2009) US Patent 2009/006979.

56. Meiswinkel A, Wöhl A, Müller W, Bölt HV, Mosa FM, Al-Hazmi MH (2012) Oil Gas Eur Mag 2:103-106.

57. Zilbershtein TM, Kardash VA, Suvorova VV, Golovko AK (2014) Appl Catal A Gen 475:371-378.

58. Dixon JT, Green MJ, Hess, FM, Morgan DH (2004) J Organomet Chem 689:3641-3668.

59. Wass DF (2002) WO Patent 02/04119.

60. Carter A, Cohen SA, Cooley NA, Murphy A, Scutt J, Wass DF (2002) Chem Commun 858-859.

61. Blann K, Bollmann A, Dixon JT, Neveling A, Morgan DH, Maumela H, Killian E, Hess FM, Otto S, Pepler L, Mahomed HA, Overett M, Green MJ (2004) WO Patent 2004/056478.

62. Bollmann A, Blann K, Dixon JT, Hess FM, Killian E, Maumela H, McGuinness DS, Morgan DH, Neveling A, Otto S, Overett M, Slawin AMZ, Wasserscheid P, Kuhlmann S (2004) J Am Chem Soc 126:14712-14713.

63. http://www.sasol.com/media-centre/media-releases/sasol-build-world\%E2\%80\%99s-first-ethylene-

tetramerisation-unit

64. Ziegler K, Martin H (1960) US Patent 2943125.

65. Yamada S, Ono I (1970) Bull Jpn Petrol Inst 12:160-163.

66. Commereuc D, Chauvin Y, Gaillard J, Léonard J, Andrews J (1984) Hydrocarbon processing 63:118-120.

67. The Alphabutol process is licensed by Axens, a subsidiary company from IFP group (see : www.axens.net for more information).

68. Bre A, Chauvin Y, Commereuc D, (1986) Nouv J Chim 10:535-537.

69. Belov GP, Dzhabiev TS, Kolesnikov IM (1982) J Mol Catal 14:105-112.

70. Suttil JA, McGuinness DS (2012) Organometallics 31:7004-7010.

71. Robinson R, McGuinness DS, Yates BF (2013) ACS Catal 3:3006-3015.

72. Deckers PJW, Hessen B, Teuben JH (2001) Angew Chem Int Ed 40:2516-2519.

73. Deckers PJW, Hessen B, Teuben JH (2002) Organometallics 21:5122-5135.

74. Blok ANJ, Budzelaar PHM, Gal AW (2003) Organometallics 22:2564-2570.

75. de Bruin TJM, Magna L, Raybaud P, Toulhoat H (2003) Organometallics 22:3404-3413.

76. Tobisch S, Ziegler T (2003) Organometallics 22:5392-5405.

77. Otten O, Batinas AA, Meetsma A, Hessen B (2008) J Am Chem Soc 131:5298-5312.

78. de Bruin TJM, Raybaud P, Toulhoat H (2008) Organometallics 27:4864-4872.

79. Huang J, Wu T, Qian Y(2003) Chem Commun 2816-2817.

80. Wu T, Qian Y, Huang J (2004) J Mol Catal A Chem 214:227-229.

81. Zhang Y, Ma H, Huang J (2013) J Mol Catal A Chem 373:85-95.

82. Braunstein P, Naud F (2001) Angew Chem Int Ed 40:680-699.

83. Gibson VC, Spitzmesser SK (2003) Chem Rev 103:283-316. 
84. Bradley DC, Mehrotra RC, Rothwell IP, Singh A (2001) "Alkoxo and Aryloxo derivatives of metals" Academic Press.

85. Gibson VC (1994) J Chem Soc Dalton Trans 1607-1618.

86. Cazaux JB, Braunstein P, Magna L, Saussine L, Oliver-Bourbigou H (2009) Eur J Inorg Chem 2942-2950.

87. IFPEN, unpublished results.

88. Grasset F, Cazaux JB, Magna L, Braunstein P, Oliver-Bourbigou H (2012) Dalton Trans 41:10396-10404.

89. Nguyen VH, Vendier L, Etienne M,Despagnet-Ayoub E, Breuil PAR, Magna L, Proriol D, Olivier-Bourbigou $H$, Lorber C (2012) Eur J Inorg Chem 97-111.

90. Suzuki Y, Kinoshita S, Shibahara A, Ishii S, Kawamura K, Inoue Y, Fujita T (2010) Organometallics 29:23942396.

91. Kinoshita S, Kawamura K, Fujita T (2011) Chem Asian J 6:284-290.

92. Makio H, Terao H, Iwashita A, Fujita T(2011) Chem Rev 111:2363-2449.

93. Suzuki Y, Kinoshita S, Shibahara A, Yoshimura N, Hara I, Hamada T, Kawamura K, Tsurugi K, Saito Y, Ishii S, Nakayama Y, Matsukawa N, Murata S (2010) EP Patent 2174928.

94. Sattler A, Labinger JA, Bercaw JE (2013) Organometallics 32:6899-6902.

95. Sattler A, VanderVelde DG, Labinger JA, Bercaw JE (2014) J Am Chem Soc 136:10790-10800.

96. Suttil JA, McGuinness DS, Gardiner MG, Evans SJ (2013) Dalton Trans 42:4185-4196.

97. Suttil JA, Shaw MF, McGuinness DS, Gardiner MG, Evans SJ (2013) Dalton Trans 42:9129-9138.

98. Shiraki Y, Nakamoto Y, Souma Y (2002) J Mol Catal A Chem 187:283-294.

99. Tobisch S, Ziegler T (2004) J Am Chem Soc 126:9059-9071.

100. Tobisch S, Ziegler T (2004) Organometallics 23:4077-4088.

101. Tobisch S, Ziegler T (2005) Organometallics 24:256-265.

102. Suttil JA, McGuinness DS, Evans SJ (2010) Dalton Trans 39:5278-5285.

103. Hata G (1964) J Am Chem Soc 86:3903-3903.

104. Hata G, Aoki D (1967) J Org Chem 32:3754-3758.

105. Hata G, Miyake A (1968) Bull Chem Soc Jap 41:2762-2764.

106. Yamamoto A, Morifujii K, Ikeda S, Saito T, Uchida Y, Misono A (1968) J Am Chem Soc 90:1878-1883.

107. tom Dieck H, Dietrich J (1985) Angew Chem Int Ed Eng 24:781-783.

108. Ehlers J, König WA, Lutz S, Wenz G, tom Dieck H (1988) Angew Chem Int Ed Eng 27:1556-1558.

109. Small BL, Brookhart M (1998) J Am Chem Soc 120:7143-7144.

110. Britovsek GJP, Gibson VC, Kimberley BS, Maddox PJ, McTavish SJ, Solan GA, White AJP, Williams DJ (1998) Chem Commun 849-850.

111. http://www.icis.com/resources/news/2001/12/10/152841/dupont-to-license-versipol-catalysts/

112. http://www3.aiche.org/proceedings/Abstract.aspx?PaperID=39124

113. Boudier A, Breuil PAR, Magna L, Olivier-Bourbigou H, Braunstein P (2014) Chem Commun 50:1398-1407.

114. Li L, Gomes PT (2012) Eds :Bianchini C, Cole-Hamilton DJ, van Leeuwen PWNM, Catalysis by Metal

Complexes (Springer) 36:77-197.

115. Small BL, Rios R, Fernandez ER, Carney MJ (2007) Organometallics 26:1744-1749.

116. Zhang M, Zhang W, Xiao T, Xiang J-F, Hao X, Sun WH (2010) J Mol Catal A Chem 320:92-96.

117. Irrgang T, Keller S, Maisel H, Kretschmer W, Kempe R (2007) Eur J Inorg Chem 4221-4228.

118. Song S, Zhao W, Wang L, Redshaw C, Wang F, Sun WH (2011) J Organomet Chem 696:3029-3035.

119. Rangheard C, Proriol D, Olivier-Bourbigou H, Braunstein P (2009) Dalton Trans 770-772.

120. Boudier A, Breuil PAR, Magna L, Rangheard C, Ponthus J, Olivier-Bourbigou H, Braunstein P (2011)

Organometallics 30:2640-2642.

121. Rangheard C, Olivier-Bourbigou H, Pellier E, Proriol D (2011) US Patent 2011/0009581.

122. Balogh-Hergovich E, Speier G, Réglier M, Giorgi M, Kuzmann E, Vértes A (2003) Eur J Inorg Chem 1735-

1740 .

123. Rangheard C, Olivier-Bourbigou H, Pellier E, Proriol D (2011) US Patent 2011/0009581.

124. Boudene Z, Boudier A, Breuil PAR, Olivier-Bourbigou H, Raybaud P, Toulhoat H, de Bruin T (2014) I Catal 317:153-157.

125. Ziemkowska W (2005) Coord Chem Rev 249:2176-2194.

126. IFPEN, unpublished results.

127. Calderon N, Ofstead EA, Ward, JP, Judy WA, Scott KW (1968) J Am Chem Soc 4133-4140.

128. Menapace HR, Maly NA, Wang JL, Wideman LG (1975) J Org Chem 40:2983-2985.

129. Maly NA, Benner GS, Menapace HR (1974) US Patent 3903193.

130. Wideman LG (1974) US Patent 3813453. 
131. Maly NA, Benner GS, Menapace HR (1974) US Patent 3784629.

132. Maly NA, Benner GS, Menapace HR (1974) US Patent 3784630.

133. Maly NA, Benner GS, Menapace HR (1974) US Patent 3784631.

134. Olivier H, Laurent-Gérot P (1999) I Mol Catal A Chem 148:43-48.

135. Tobisch S (2007) Organometallics 26:6529-6532.

136. Tobisch S (2008) Dalton Trans 2120-2127.

137. Wright WRH, Batsanov AS, Howard JAK, Tooze RP, Hanton MJ, Dyer PW (2010) Dalton Trans 39:70387045.

138. Hanton MJ, Daubney L, Leb| T, Polas S, Smith DM, Willemse A (2010) Dalton Trans 7025-7037.

139. Tooze RP, Hanton MJ (2007) US Patent 2007/287872. 